\title{
Cochrane
}

Library

Cochrane Database of Systematic Reviews

\section{Radical multimodality therapy for malignant pleural mesothelioma} (Review)

Abdel-Rahman O, Elsayed Z, Mohamed H, Eltobgy M

Abdel-Rahman O, Elsayed Z, Mohamed H, Eltobgy M.

Radical multimodality therapy for malignant pleural mesothelioma.

Cochrane Database of Systematic Reviews 2018, Issue 1. Art. No.: CD012605.

DOI: 10.1002/14651858.CD012605.pub2.

www.cochranelibrary.com

Radical multimodality therapy for malignant pleural mesothelioma (Review) 
TABLE OF CONTENTS

ABSTRACT

PLAIN LANGUAGE SUMMARY

SUMMARY OF FINDINGS

BACKGROUND

OBJECTIVES

METHODS

Figure 1.

RESULTS

Figure 2.

Figure 3.

DISCUSSION

AUTHORS' CONCLUSIONS

ACKNOWLEDGEMENTS

REFERENCES

CHARACTERISTICS OF STUDIES

APPENDICES

CONTRIBUTIONS OF AUTHORS

DECLARATIONS OF INTEREST

SOURCES OF SUPPORT

DIFFERENCES BETWEEN PROTOCOL AND REVIEW

INDEX TERMS

1

2

3

6

8

8

10

12

14

15

16

17

17

18

21

26

30

30

30

30

30 
[Intervention Review]

\section{Radical multimodality therapy for malignant pleural mesothelioma}

Omar Abdel-Rahman¹, Zeinab Elsayed ${ }^{1}$, Hadeer Mohamed², Mostafa Eltobgy²

${ }^{1}$ Clinical Oncology, Faculty of Medicine, Ain Shams University, Cairo, Egypt. 2Faculty of Medicine, Ain Shams University, Cairo, Egypt

Contact: Omar Abdel-Rahman, Clinical Oncology, Faculty of Medicine, Ain Shams University, Lofty Elsayed Street, Cairo, 11335, Egypt. omar.abdelrhman@med.asu.edu.eg, omar_abdelsalam80@yahoo.com.

Editorial group: Cochrane Lung Cancer Group.

Publication status and date: New, published in Issue 1, 2018.

Citation: Abdel-Rahman O, Elsayed Z, Mohamed H, Eltobgy M. Radical multimodality therapy for malignant pleural mesothelioma. Cochrane Database of Systematic Reviews 2018, Issue 1. Art. No.: CD012605. DOI: 10.1002/14651858.CD012605.pub2.

Copyright (c) 2018 The Cochrane Collaboration. Published by John Wiley \& Sons, Ltd.

\section{A B S T R A C T}

\section{Background}

Malignant pleural mesothelioma is an almost always fatal tumour, for which palliative platinum-based chemotherapy is currently the standard treatment. Multimodal therapeutic strategies incorporating surgery, radiation therapy or photodynamic therapy and chemotherapy have been recommended for selected patients but there is no consensus about their effectiveness.

\section{Objectives}

To assess the benefits and harms of radical multimodal treatment options (including radical surgery \pm radical radiotherapy \pm photodynamic therapy \pm systemic therapy) compared to each other or to palliative treatments, for people with malignant pleural mesothelioma.

\section{Search methods}

We reviewed data from the Cochrane Lung Cancer group's Specialised Register, Cochrane Central Register of Controlled Trials (CENTRAL), MEDLINE and Embase. We also checked reference lists of primary original studies, review articles and relevant conference proceedings manually for further related articles up to 21 March 2017.

\section{Selection criteria}

We included parallel-group randomised controlled trials of multimodal therapy for people with malignant pleural mesothelioma (stages I, II or III) that measured at least one of the following endpoints: overall survival, health-related health-related quality of life, adverse events or progression-free survival. We considered studies regardless of language or publication status.

\section{Data collection and analysis}

Two review authors independently extracted relevant information on participant characteristics, interventions, study outcomes, and data on the outcomes for this review, as well as information on the design and methodology of the studies. Two review authors assessed the risk of bias in the included trials using pre-defined 'Risk of bias' domains. We assessed the methodological quality using GRADE.

\section{Main results}

We conducted this review in accordance with the published Cochrane protocol. Two randomised clinical trials with 104 participants fulfilled our inclusion criteria. Both trials were at high risk of bias (for outcomes other than overall survival), and we rated the evidence as moderate quality for overall survival and low quality for all other outcomes. One trial compared combined extrapleural pneumonectomy (EPP) plus neoadjuvant platinum-based chemotherapy plus postoperative high-dose hemithoracic radiotherapy with combined EPP plus platinum-based chemotherapy. The other trial compared EPP plus postoperative hemithoracic radiotherapy with standard (nonradical) therapy alone following platinum-based chemotherapy (patients in the standard therapy arm received continued oncological management according to local policy, which could include further chemotherapy or palliative radiotherapy). 
For the first trial, median overall survival calculated from registration was 20.8 months (95\% confidence interval (Cl) 14.4 to 27.8$)$ in the noradiotherapy group and 19.3 months $(95 \% \mathrm{Cl} 11.5$ to 21.8$)$ in the radiotherapy group. For the second trial, median overall survival was 14.4 months $(95 \% \mathrm{Cl} 5.3$ to 18.7$)$ for patients allocated to EPP and 19.5 months (95\% $\mathrm{Cl} 13.4$ to time not yet reached) for patients randomised to standard non-radical therapy. In the second trial, 12 serious adverse events were reported during the study period: ten in the EPP group and two in the non-radical therapy group. Overall health-related quality of life scores were not different between the two arms in either study. We could not perform a meta-analysis of the two included trials due to clinical heterogeneity. We also identified three ongoing trials evaluating the topic of our review.

\section{Authors' conclusions}

The overall strength of the evidence gathered in this review is low and there is a lack of available evidence to support the use of radical multimodality therapy in routine clinical practice (particularly as one trial suggests greater harm). Given the added cost of multimodality treatment and the possible increase in risk of adverse effects, the lack of evidence of their effectiveness probably means that these interventions should currently be limited to clinical trials alone.

\section{PLAIN LANGUAGE SUMMARY}

\section{Multimodality treatment for malignant pleural mesothelioma (primary pleural cancer)}

\section{Review question}

Does radical surgery with or without radiotherapy improve the length and health-related quality of life in people with localised malignant mesothelioma, compared with chemotherapy and supportive care only?

\section{Background}

Malignant pleural mesothelioma (that is, primary pleural cancer) is a difficult tumour to treat. Chemotherapy is usually given first to people who are fit enough to have it. It is not clear whether radical surgery and radiotherapy help people to live longer or improve their overall health-related quality of life.

\section{Study characteristics}

We searched published medical articles to find research papers that looked at combined treatment strategies with surgery for treating people with primary pleural cancer. We looked for randomised clinical trials (where people were allocated at random to one of two or more treatments groups) and used information from those we found to form our conclusions. We found evidence up to $21 \mathrm{March} 2017$.

\section{Key results}

The review authors found two small randomised clinical trials, in which a total of 104 people with pleural mesothelioma were randomised. One trial compared the addition of surgery and radiotherapy to chemotherapy with chemotherapy alone. The other trial compared the addition of radiotherapy to chemotherapy and surgery with chemotherapy and surgery alone. These two small trials suggested that there is no added value for either radiotherapy or combined radiotherapy and surgery. We could not combine the data from the trials as we had intended, because the two trials were too different. We rated the quality of evidence as moderate for survival and low quality for all the other outcomes studied. The review authors identified three ongoing randomised clinical trials, the results of which have not been published yet.

\section{Quality of evidence and conclusions}

We only found two relevant trials. Both were small, which made the results uncertain. It is not clear whether giving a combination of surgery and radical radiotherapy after chemotherapy is better than giving chemotherapy alone. Radical radiotherapy does not seem to improve the results of surgery alone. 


\begin{tabular}{|c|c|c|c|c|c|c|c|}
\hline \multirow{11}{*}{ 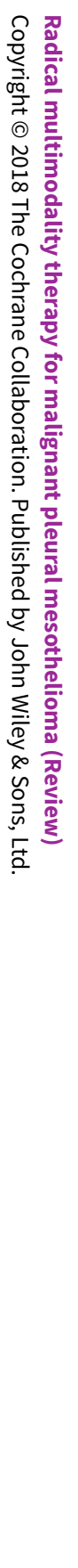 } & \multicolumn{7}{|c|}{$\begin{array}{l}\text { S U M M ARY O F F I N D I N G S } \\
\text { Summary of findings for the main comparison. }\end{array}$} \\
\hline & \multicolumn{7}{|c|}{$\begin{array}{l}\text { Combined EPP plus neoadjuvant platinum-based chemotherapy plus post operative high-dose hemithoracic radiotherapy compared with combined EPP plus } \\
\text { neoadjuvant platinum-based chemotherapy for malignant pleural mesothelioma }\end{array}$} \\
\hline & \multicolumn{7}{|c|}{$\begin{array}{l}\text { Patient or population: people with malignant pleural mesothelioma } \\
\text { Settings: specialist hospital } \\
\text { Intervention: combined EPP plus neoadjuvant platinum-based chemotherapy plus postoperative high-dose hemithoracic radiotherapy } \\
\text { Comparison: combined EPP plus neoadjuvant platinum-based chemotherapy }\end{array}$} \\
\hline & \multirow[t]{3}{*}{ Outcomes } & \multicolumn{2}{|c|}{ Illustrative comparative risks* $(95 \% \mathrm{CI})$} & \multirow{3}{*}{$\begin{array}{l}\text { Relative effect } \\
(95 \% \mathrm{CI})\end{array}$} & \multirow{3}{*}{$\begin{array}{l}\text { No of Partici- } \\
\text { pants } \\
\text { (studies) }\end{array}$} & \multirow{3}{*}{$\begin{array}{l}\text { Quality of the } \\
\text { evidence } \\
\text { (GRADE) }\end{array}$} & \multirow[t]{3}{*}{ Comments } \\
\hline & & Assumed risk & Corresponding risk & & & & \\
\hline & & $\begin{array}{l}\text { combined EPP plus } \\
\text { chemotherapy }\end{array}$ & $\begin{array}{l}\text { combined EPP plus chemotherapy plus } \\
\text { hemithoracic radiotherapy }\end{array}$ & & & & \\
\hline & $\begin{array}{l}\text { Median overall } \\
\text { survival }\end{array}$ & $\begin{array}{l}20.8 \text { months }(95 \% \mathrm{Cl} 14.4 \text { to } \\
27.8)\end{array}$ & 19.3 months ( $95 \% \mathrm{Cl} 11.5$ to 21.8 ) & - & $54(1)$ & $\begin{array}{l}\oplus \oplus \oplus \ominus \\
\text { Moderate } 1\end{array}$ & \\
\hline & $\begin{array}{l}\text { Health-related } \\
\text { health-related } \\
\text { quality of life }\end{array}$ & \multicolumn{2}{|c|}{$\begin{array}{l}\text { No changes in the scores for the overall evaluation of life in both groups up } \\
\text { to week } 14 \text { after randomisation }\end{array}$} & - & $54(1)$ & $\begin{array}{l}\oplus \oplus \odot \odot \\
\text { Low }^{2}\end{array}$ & \\
\hline & Adverse events & \multicolumn{2}{|c|}{$\begin{array}{l}\text { The following adverse events were observed in the radiotherapy arm: } \\
\text { anaemia ( } 74 \%) \text {, nausea or vomiting ( } 44 \%) \text {, oesophagitis ( } 29 \%) \text {, fatigue } \\
(24 \%) \text {, weight loss (19\%), dyspnoea ( } 4 \%) \text {, diarrhoea ( } 4 \%) \text {, and increased al- } \\
\text { kaline phosphatase concentration ( } 4 \%) \text {. } \\
\text { There was no comment on the adverse events in the no radiotherapy arm. }\end{array}$} & - & $54(1)$ & $\begin{array}{l}\oplus \oplus \odot \ominus \\
\text { Low }^{2}\end{array}$ & \\
\hline & $\begin{array}{l}\text { Postoperative } \\
\text { complications }\end{array}$ & \multicolumn{2}{|c|}{$\begin{array}{l}\text { Postoperative complications included mediastinal shift (11\%), major in- } \\
\text { fections ( } 8 \% \text { ), bleeding }(6 \%) \text {, bronchial stump fistula( } 3 \%) \text {, pulmonary em- } \\
\text { bolism, chylothorax, and technical failures ( } 2 \% \text { each). It was not classified } \\
\text { in the trial based on treatment arms }\end{array}$} & - & $54(1)$ & $\begin{array}{l}\oplus \oplus \odot \odot \\
\text { Low }^{2}\end{array}$ & \\
\hline & $\begin{array}{l}\text { Treatment-re- } \\
\text { lated death }\end{array}$ & None reported. & $\begin{array}{l}\text { One patient died of a complicated pneu- } \\
\text { monia during radiotherapy, which was } \\
\text { probably related to treatment. }\end{array}$ & - & $54(1)$ & $\begin{array}{l}\oplus \oplus \ominus \ominus \\
\text { Low }^{2}\end{array}$ & \\
\hline
\end{tabular}




\begin{tabular}{|c|c|c|c|c|c|c|}
\hline \multicolumn{7}{|c|}{$\begin{array}{l}{ }^{\star} \text { The basis for the assumed risk (e.g. the median control group risk across studies) is provided } \\
\text { based on the assumed risk in the comparison group and the relative effect of the intervention } \\
\text { CI: Confidence interval; EPP: extrapleural pneumonectomy. }\end{array}$} \\
\hline \multicolumn{7}{|c|}{$\begin{array}{l}\text { GRADE Working Group grades of evidence } \\
\text { High quality: Further research is very unlikely to change our confidence in the estimate of effect. } \\
\text { Moderate quality: Further research is likely to have an important impact on our confidence in the estimate of effect and may change the estimate. } \\
\text { Low quality: Further research is very likely to have an important impact on our confidence in the estimate of effect and is likely to change the estimate. } \\
\text { Very low quality: We are very uncertain about the estimate. }\end{array}$} \\
\hline \multicolumn{7}{|c|}{$\begin{array}{l}\text { 1Due to imprecision, the quality of the evidence was assessed as moderate. } \\
\text { 2Due to imprecision as well as high risk of bias, the quality of the evidence was assessed as low. }\end{array}$} \\
\hline \multicolumn{7}{|c|}{$\begin{array}{l}\text { Combined platinum-based chemotherapy plus EPP plus postoperative hemithoracic radiotherapy compared with chemotherapy for malignant pleural mesothe- } \\
\text { lioma }\end{array}$} \\
\hline \multicolumn{7}{|c|}{$\begin{array}{l}\text { Patient or population: people with malignant pleural mesothelioma } \\
\text { Settings: specialist hospital } \\
\text { Intervention: combined chemotherapy plus EPP plus postoperative hemithoracic radiotherapy } \\
\text { Comparison: chemotherapy }\end{array}$} \\
\hline \multirow[t]{3}{*}{ Outcomes } & Illustrative comparative risks ${ }^{\star}$ & Cl) & \multirow{3}{*}{$\begin{array}{l}\text { Relative effect } \\
(95 \% \mathrm{Cl})\end{array}$} & \multirow{3}{*}{$\begin{array}{l}\text { No of Partici- } \\
\text { pants } \\
\text { (studies) }\end{array}$} & \multirow{3}{*}{$\begin{array}{l}\text { Quality of the } \\
\text { evidence } \\
\text { (GRADE) }\end{array}$} & \multirow[t]{3}{*}{ Comments } \\
\hline & Assumed risk & Corresponding risk & & & & \\
\hline & Chemotherapy & $\begin{array}{l}\text { Combined chemotherapy plus } \\
\text { EPP plus postoperative hemitho- } \\
\text { racic radiotherapy }\end{array}$ & & & & \\
\hline $\begin{array}{l}\text { Median overall } \\
\text { survival }\end{array}$ & $\begin{array}{l}19.5 \text { months }(95 \% \mathrm{Cl} 13.4 \text { to time- } \\
\text { not-yet reached) }\end{array}$ & 14.4 months ( $95 \% \mathrm{Cl} 5.3$ to 18.7 ) & - & $50(1)$ & $\begin{array}{l}\oplus \oplus \oplus \odot \\
\text { Moderate } \\
1\end{array}$ & \\
\hline $\begin{array}{l}\text { Health-related } \\
\text { health-related } \\
\text { quality of life }\end{array}$ & $\begin{array}{l}\text { There were no statistically signific } \\
\text { groups }\end{array}$ & differences between treatment & - & $50(1)$ & $\begin{array}{l}\oplus \oplus \odot \odot \\
\text { Low }^{2}\end{array}$ & \\
\hline
\end{tabular}




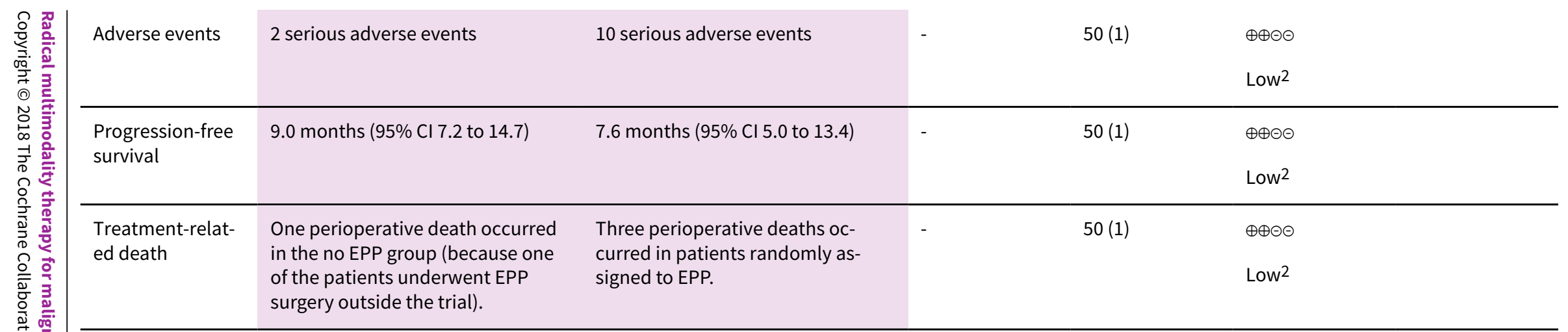

*The basis for the assumed risk (e.g. the median control group risk across studies) is provided in footnotes. The corresponding risk (and its $95 \%$ confidence interval) is based on the assumed risk in the comparison group and the relative effect of the intervention (and its $95 \% \mathrm{Cl}$ ).

Cl: Confidence interval; EPP: extrapleural pneumonectomy

GRADE Working Group grades of evidence

High quality: Further research is very unlikely to change our confidence in the estimate of effect.

Moderate quality: Further research is likely to have an important impact on our confidence in the estimate of effect and may change the estimate.

Low quality: Further research is very likely to have an important impact on our confidence in the estimate of effect and is likely to change the estimate.

Very low quality: We are very uncertain about the estimate.

1Due to imprecision, the quality of the evidence was assessed as moderate.

2Due to imprecision as well as high risk of bias, the quality of the evidence was assessed as low. 


\section{B A C K G R O U N D}

\section{Description of the condition}

Mesothelioma is a malignant tumour arising from the mesothelial cells lining the pleura (65\% to $70 \%$ ), peritoneum (30\%), pericardium or testis (1\% to $2 \%$ ) (Bridda 2007). The major histological subtypes of mesothelioma include sarcomatoid, epithelioid and biphasic. Malignant pleural mesothelioma (MPM) is an almost always fatal tumour. The peak incidence is in the fifth and sixth decades of life and it more commonly affects men (Mott 2012). Amphibole asbestos is implicated in the carcinogenesis of MPM in many cases. Other possible aetiological factors include simian virus 40 , exposure to radiation and erionite (Robinson 2012). Genetic factors may also play a role; for instance BAP1 tumour predisposition syndrome (BAP1-TPDS) is associated with many malignancies including malignant mesothelioma. Somatic mutations may be also linked to MPM development (Testa 2011).

The incidence of MPM varies around the world. The highest rates (up to 30 cases per million population) are in industrialised countries-especially Australia, the UK and Belgium-associated either with mining of the mineral or with high usage in many industries until the 1980s. The incidence of MPM is expected to rise between 2015 and 2025 (Bianchi 2007; Robinson 2012). Based on the World Health Organization (WHO) mortality data for 1994 to 2008, the crude and age-adjusted mortality rates for all mesothelioma deaths were 6.2 and 4.9 per million population, respectively. It has also been predicted that the increasing and poorly regulated use of asbestos in low-income countries will mean that numbers of mesothelioma-related deaths in those countries will increase in the next decades (Algranti 2015).

The diagnosis of MPM is problematic because the disease presents with vague symptoms: between $10 \%$ and $90 \%$ of people present with either dyspnoea or chest pain; other symptoms include: a long history of pleural effusion without definitive cytology, systemic symptoms such as tiredness, fever, sweats or weight loss. Mesothelioma may also be asymptomatic (Chapman 2006).

Overall, the prognosis of people with MPM is poor, with a median overall survival rate of between six and nine months from diagnosis; fewer than 5\% survive to five years (Van Meerbeeck 2011). According to the WHO classification of pleural tumours for 2015, sarcomatoid and biphasic subtypes have poorer prognoses than the epithelioid subtype (Galateau-Salle 2016). However, the pleomorphic epithelioid subtype has been shown to have worse outcomes than all other epithelioid subtypes and similar survival to sarcomatoid and biphasic subtypes (Brčić 2014; Kadota 2011).

Several staging systems are used for MPM (Chapman 2006). The tumour/node/metastasis (TNM) staging system proposed by the International Mesothelioma Interest Group (IMIG) was used until recently (Armato 2013) but was replaced in 2016 by a new TNM staging system (Rusch 2016; Abdel-Rahman 2017c).

Computerised tomography (CT) of the chest with contrast is the standard imaging method for evaluating the extent of the pleural disease; magnetic resonance imaging (MRI) is recommended only in special situations when more precise delineation of the tumour is needed (Heelan 1999). Positron emission tomography (PET) scanning may sometimes be used for localisation of tumour sites, distant metastases or early response to treatment as part of a research protocol (Baas 2015).

A number of different therapeutic strategies are used in the management of people with MPM. Treatment choice depends on patient- and disease-related factors (Baas 2015). Therapies can be broadly classified into those with palliative intent and those with curative (or radical) intent.

\section{Palliative strategies}

Palliative strategies include radiotherapy, chemotherapy, pleurodesis (obliterating the potential pleural space by introducing a sclerosing substance) and pain control. Palliative strategies are more likely to be used in older, frail people with poor performance status or advanced disease that cannot be managed by other local therapies.

\section{Palliative radiotherapy}

Palliative radiotherapy is aimed at relieving pain from tumour growth (Baas 2015). However, recent studies have shown no compelling evidence supporting its routine use (Macleod 2014; MacLeod 2015). Radiotherapy was also evaluated with the intent of preventing instrumentation track metastases (Eastment 2017).

\section{Curative (radical) strategies}

Surgical resection (either extrapleural pneumonectomy or pleurectomy/decortication) can be preceded or followed by chemotherapy, radiotherapy, or both. In this review, radical multimodality therapy will mean the use of a combination of radical surgery together with other local or systemic therapies (or both) with the aim of eradicating the disease. This shall include surgery \pm radiotherapy \pm photodynamic therapy \pm systemic therapy.

\section{Surgical resection}

There are two principal surgical approaches used with curative intent: extrapleural pneumonectomy (EPP) and pleurectomy/ decortication (P/D) (Bertoglio 2016).

\section{Peri-operative radiotherapy}

It has been suggested that peri-operative radiotherapy (particularly using newer radiotherapy techniques such as intensity modulated radiation therapy) may reduce the probability of tumour recurrence after surgery and improve patient outcomes (AbdelRahman 2017a). Initially, a phase II trial evaluating postoperative radiotherapy with a dose of 54 gray (Gy) to patients who underwent extrapleural pneumonectomy or pleurectomy/ decortication showed a 17-month median survival which was longer than historical cases (Rusch 2001). Another study has shown that radiation therapy after EPP may be associated with fatal pneumonitis (Allen 2006). Pre-operative radiotherapy followed by EPP has been evaluated in a single arm phase II trial in patients with epithelioid type but this approach will need further evaluation on a large randomised trial (De Perrot 2016).

\section{Peri-operative chemotherapy}

Pre- and postoperative chemotherapy may reduce the risk of local and distant relapse of MPM. Pre-operative (induction) treatment may decrease tumour volume and make radical surgical resection more possible. Some studies have evaluated the concept of trimodality therapy (induction chemotherapy followed by surgery 
and postoperative radiotherapy). Despite promising results from single arm phase II studies (Van Schil 2010; Weder 2012), the effectiveness of this approach has not been confirmed (Stahel 2016; Treasure 2011).

\section{Intra-operative photodynamic therapy}

Intra-operative photodynamic therapy has been combined with pleurectomy/decortication and chemotherapy in one retrospective study (Friedberg 2017). The same design is being evaluated in a number of prospective studies and the results are awaited.

\section{Surgical resection}

The aim of surgery for people with MPM is macroscopic resection of as much visible tumour as possible. In the past, terms such as extra-pleural pleurectomy and pleurectomy/decortication have been used without adequate or agreed definitions. However, most international guidelines do not support the routine use of surgery for people with MPM outside clinical trial settings (Baas 2015; Scherpereel 2010). The following definitions of surgery have been proposed:

- EPP-removal of the lung, a portion of the diaphragm, and the parietal and visceral pleura and pericardium;

- Extended P/D-is the same procedure as EPP but the lung is left in situ;

- $P / D$ or total pleurectomy-removal of all gross tumour without resection of the diaphragm or the pericardium; and

- Partial pleurectomy-removal of parietal or visceral pleura or both without removal of the gross tumour (Rusch 2016).

Potential harms arising from surgery may include: bleeding, venous thromboembolism, pulmonary complications (such as respiratory distress, pulmonary infections), cardiac complications (such as atrial fibrillation and myocardial infarction) and gastrointestinal complications (such as nausea, vomiting, paralytic ileus) (Sugarbaker 1999).

\section{Radiation therapy}

Radiation therapy aims to achieve maximum tumour control with minimal risk of normal tissue damage. This aim has been enhanced by the use of newer technologies such as intensity modulated radiation therapy and image-guided radiation therapy (Runxiao 2016).

Radiation may be used as an adjuvant therapy after surgery or as part of trimodality approach including chemotherapy and surgery. But it is not yet recommended as a standard treatment (Baas 2015). The rationale for perioperative radiotherapy in MPM is to promote local control by eradicating microscopic disease at the site of surgery (Abdel-Rahman 2017a).

The possible side effects of thoracic radiotherapy for pleural mesothelioma may include pneumonitis, oesophagitis, skin reactions and acute and delayed cardiac effects (Allen 2006).

\section{Chemotherapy}

Chemotherapy is the first and second line of treatment of unresectable tumours. Following the publication of a large randomised trial in 2003, the combination of pemetrexed and cisplatin has been considered the standard systemic therapy for MPM (Vogelzang 2003). This combination has been used in most studies evaluating triple modality therapy with surgical resection and postoperative radiation therapy. Pemetrexed is a folate antimetabolite that interferes with nucleic acid synthesis (Manegold 2003); cisplatin works by interfering with DNA replication (Pruefer 2008). The rationale for using perioperative chemotherapy is to promote local and systemic control of the disease through eradicating disease both at the site of surgery as well as in other parts of the body. Preoperative chemotherapy may also increase the resectability of MPM (Abdel-Rahman 2015).

Expected toxicities following cytotoxic chemotherapy include myelosuppression, asthenia, nausea and vomiting, renal and hepatic toxicities (Vogelzang 2003; Zalcman 2016). When combined with bevacizumab, additional toxicities might include hypertension and thromboembolic events (Zalcman 2016).

\section{Immunotherapy}

Immune checkpoint inhibitors are considered one of the most important advances in cancer management in the past decade. They work by inhibiting immune checkpoints including cytotoxic Tlymphocyte antigen 4 (CTLA-4) or programmed cell death protein-1 (PD-1) or its ligand (PD-L1); thus, they would enhance the antitumour activity of cytotoxic T- lymphocytes (Mohamed 2017; Wolchok 2013). A number of early phase clinical studies have been recently reported evaluating the use of some immune checkpoint inhibitors in the management of MPM (Calabro 2013; Calabro 2015).

\section{Photodynamic therapy}

Intra-operative photodynamic therapy works by directly targeting residual disease in the pleural space following lung-sparing surgical interventions (Friedberg 2012). It is a form of phototherapy that aims to cause cell death and involves the combined use of light and a chemical substance with photosensitising properties, in conjunction with molecular oxygen (Saini 2016). Together with other local and systemic therapies for MPM, it may enhance local control of the disease (Friedberg 2012).

\section{Description of the intervention}

In this review, radical multimodality therapy for malignant pleural mesothelioma means the use of a combination of radical surgery together with other local or systemic therapies (or both) with the aim of eradicating the disease. This includes radical surgery \pm radical radiotherapy \pm photodynamic therapy \pm systemic therapy.

\section{How the intervention might work}

Radical multimodality therapy for MPM (including radical surgery \pm radical radiotherapy \pm photodynamic therapy \pm systemic therapy) might provide better outcomes, including symptom control and survival, than single modality of treatment. Given the poor results of using chemotherapy alone in the management of MPM, and its localised nature in the majority of cases, it has long been suggested that combining aggressive local treatment with systemic chemotherapy might improve the outcomes (Hiddinga 2013). This theoretical basis was supported by the results of a number of nonrandomised studies which suggested that adding more aggressive local therapy (including surgery and radiation therapy) might improve the outcomes of this disease (Flores 2008; Schipper 2008). 


\section{Why it is important to do this review}

The prognosis of MPM is generally poor and studies that explored the multimodality treatment protocols incorporating local therapies and systemic therapies have shown conflicting results and a 'best strategy' has not yet been agreed. Moreover, the cost of multimodality treatment is higher than for single therapies. For all these reasons, it is important to do this review to clarify the value of radical multimodality therapy for MPM.

\section{OB JECTIVES}

To assess the benefits and harms of radical multimodal treatment options (including radical surgery \pm radical radiotherapy \pm photodynamic therapy \pm systemic therapy) compared to each other or to palliative treatments, for people with malignant pleural mesothelioma.

\section{METHODS}

\section{Criteria for considering studies for this review}

\section{Types of studies}

We included parallel-group randomised controlled trials (RCTs) of multimodal therapy for people with malignant pleural mesothelioma that measured at least one of the following endpoints: overall survival, progression-free survival, healthrelated health-related quality of life (HR QoL), or adverse events. We considered studies regardless of language or publication status.

\section{Types of participants}

Patients with histologically diagnosed non-metastatic malignant pleural mesothelioma (stages I, II or III) were included.

\section{Types of interventions}

We assessed radical multimodality therapy including any combinations of radical surgery (including extrapleural pneumonectomy and pleurectomy/decortication), radical radiation therapy, photodynamic therapy and chemotherapy.

We considered the following comparisons.

Radical multimodality treatments versus palliative treatment:

- Surgery combined with chemotherapy compared with chemotherapy alone;

- Surgery combined with radiotherapy and chemotherapy compared with chemotherapy alone;

- Surgery combined with radiotherapy, chemotherapy and photodynamic therapy compared with chemotherapy alone.

Comparison of different radical multimodality treatments:

- Surgery combined with radiotherapy and chemotherapy compared with chemotherapy combined with surgery;

- Surgery combined with radiotherapy, chemotherapy and photodynamic therapy compared with chemotherapy combined with surgery;

- Surgery combined with radiotherapy, chemotherapy and photodynamic therapy compared with chemotherapy combined with surgery and radiation therapy.

\section{Types of outcome measures}

We considered the following outcome measures in this review.

\section{Primary outcomes}

- Overall survival, reported either as hazard ratio or median overall survival (defined as the median time from randomisation to death from any cause), or both.

- Health-related health-related quality of life, measured using standardised and validated instruments.

- Adverse events graded according to the National Cancer Institute Common Terminology Criteria for Adverse Events (CTCAE), version 4.03 (CTCAE 2009).

\section{Secondary outcomes}

- Median progression-free survival (defined as the time from randomisation to progression of the disease or death in the absence of progression).

- Postoperative complications (including bleeding, empyema, fistula, pneumopathy, arrhythmias).

- All treatment-related deaths (including perioperative deaths or deaths due to pneumonitis or organ dysfunction).

- Locoregional and distant recurrence rates at one year.

\section{Search methods for identification of studies}

\section{Electronic searches}

We searched the following databases:

- Cochrane Lung Cancer group's Specialised Register (searched 21 March 2017);

- Cochrane Central Register of Controlled Trials (CENTRAL; 2017, Issue 3) in the Cochrane Library (searched 21 March 2017) (Appendix 1);

- MEDLINE, accessed via PubMed (1946 to 21 March 2017) (Appendix 2); and

- Embase (Ovid SP) (1980 to 21 March 2017) (Appendix 3).

We performed the search of MEDLINE using the Cochrane highly sensitive search strategy-Sensitivity maximising version (2008 revision) as described in the Cochrane Handbook for Systematic Reviews of Interventions (Higgins 2011).

We also conducted a search of ClinicalTrials.gov (www.ClinicalTrials.gov) and the World Health Organization (WHO) trials portal (http://apps.who.int/trialsearch/) (17 April 2017). We did not impose language or publication restrictions.

\section{Searching other resources}

We handsearched reference lists of included studies, relevant chapters and review articles for trials of interest. We searched conference proceedings of relevant oncology, pulmonology and thoracic surgery meetings (from 2013 to March 2017).

\section{Data collection and analysis}

We summarised data using Cochrane's standard methodologies (Higgins 2011). We performed the analyses using Review Manager 5.3 (RevMan 2014). 


\section{Selection of studies}

Two review authors (HM, ME) independently screened titles and abstracts of all the studies identified as a result of the search for inclusion.

We retrieved the full-text study reports/publications and two review authors (HM, ME) independently screened the full-text and identified studies for inclusion, and identified and recorded reasons for exclusion of the ineligible studies. We resolved any disagreement through discussion, or if required, we consulted a third review author (ZE). We identified and excluded duplicates and collated multiple reports of the same study so that each study rather than each report is the unit of interest in the review. We recorded the selection process in sufficient detail to complete a PRISMA flow diagram (Moher 2009), (Figure 1) and 'Characteristics of excluded studies' table (Characteristics of excluded studies). We did not impose any language restrictions. 
Figure 1. Study flow diagram.

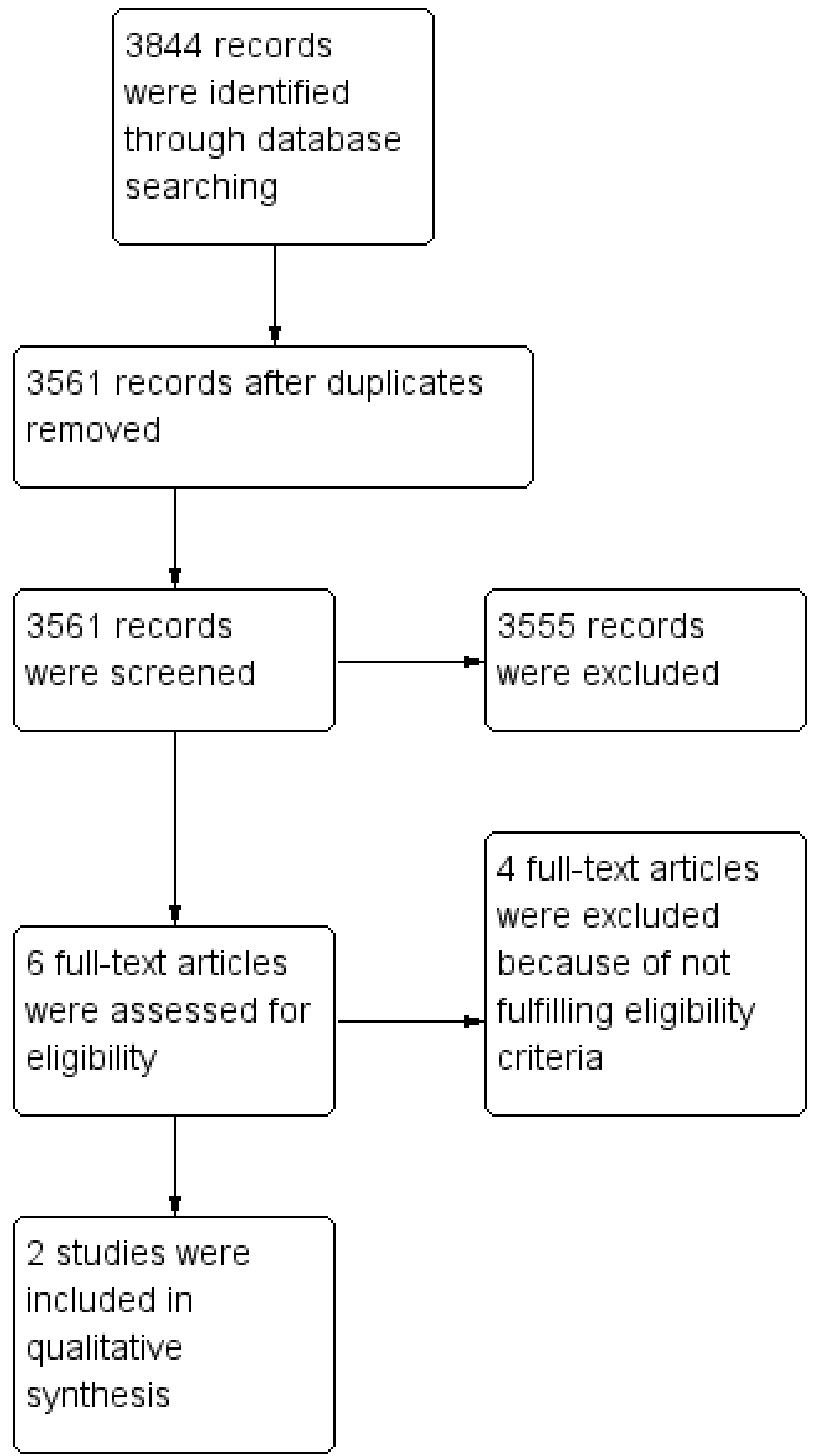

\section{Data extraction and management}

We used a data collection form for study characteristics and outcome data, which was piloted on at least one study in the review. One review author (ME) extracted study characteristics from included studies and this was cross-checked by another review author (HM). We extracted the following study characteristics. 
- Methods: study design, total duration of study, details of any runin period, number of study centres and their locations, study setting, withdrawals, and date of study.

- Participants: N, mean age, age range, gender, stage, diagnostic criteria, inclusion criteria, and exclusion criteria.

- Interventions: intervention, comparison, concomitant medications, and excluded medications.

- Outcomes: primary and secondary outcomes specified and collected (see Primary outcomes; Secondary outcomes), and time points reported.

- Notes: funding for trial, and notable conflicts of interest of trial authors.

Two review authors (HM, ME) independently extracted outcome data from included studies. We noted in the 'Characteristics of included studies' table (Characteristics of included studies) if outcome data were not reported in a usable way. We resolved disagreements by consensus or by involving a third review author (OA). One review author (ME) transferred data into the Review Manager file (RevMan 2014). We double-checked that data were entered correctly by comparing the data presented in the systematic review with the study reports. A second review author (HM) checked study characteristics for accuracy against the trial report.

\section{Assessment of risk of bias in included studies}

Two review authors (HM, ME) independently assessed the included studies for risk of bias using Cochrane's 'Risk of bias' tool (Higgins 2011). We assessed risk of bias according to the following six domains for all included studies, assigning assessments as low, unclear or high risk of bias.

\section{Random sequence generation}

- Sequence was generated using a random number table or a computer (low risk of bias).

- Sequence generation method was not specified even if the trial was stated to be randomised (unclear risk of bias).

- Sequence generation method applied a non-random process, e.g. hospital record number, dates of birth or admission (high risk of bias).

\section{Allocation concealment}

- Allocation could not have been foreseen in advance of or during enrolment. Allocation was controlled by a centralised system or undertaken using consecutively numbered sealed opaque envelopes (low risk of bias).

- Method used to conceal allocation was not described even if the trial was stated to be randomised (unclear risk of bias).

- Trial was not blinded; allocation was known during the trial (high risk of bias).

\section{Blinding of participants, personnel and outcome assessors}

- Effective double or triple-blind designs are sometimes not appropriate for use in anticancer therapy trials because of toxicity risks; moreover, radiotherapy cannot be blinded. We assessed risk of bias separately for personnel, participants, outcomes assessors and different outcomes, as applicable.

\section{Incomplete outcome data}

- Missing data were unlikely to deviate treatment effects from plausible values. Sufficient methods, such as multiple imputation, were employed to handle missing data (low risk of bias).

- Insufficient information to assess if missing data together with methods used to handle missing data were likely to induce bias on results (unclear risk of bias).

- Demonstration that: results were likely to be biased due to missing data, or reasons for missing outcome data were likely to be related to the true outcome, or imbalance in numbers or reasons for missing data among intervention groups; or for dichotomous outcome data, the proportion of missing outcomes compared with observed event risk was sufficient to induce clinically-relevant bias in the intervention effect estimate; or for continuous outcome data, plausible effect size (difference in mean or standardised mean difference) among missing outcomes was sufficient to induce clinically-relevant bias in observed effect size; or as-treated analysis conducted with substantial departure from the intervention assigned at randomisation to intervention; or potentially inappropriate application of simple imputation (high risk of bias).

\section{Selective outcome reporting}

- If the original trial protocol was available, the outcomes should be those called for in that protocol. If no protocol was available, then outcomes listed in the methods section of an article should be those whose results are reported (low risk of bias).

- Outcomes defined in the study protocol (or the article methods section if the protocol is not available) were not reported fully in the study report, or it was unclear if data on these outcomes were recorded (unclear risk of bias).

- High risk: one or more pre-defined outcomes in the protocol (or the article methods section if the protocol is not available) were not reported.

\section{Other sources of bias}

- Trial appeared to be free of other bias domains that could put it at risk of bias (low risk of bias).

- Trial may or may not have been free of other bias domains that could put it at risk of bias (unclear risk of bias).

- There were other factors in the trial that could put it at risk of bias.

We assessed trials to be at overall low risk of bias if all domains were assessed at low risk of bias. We assessed trials to be at high risk of bias if assessed as unclear or high risk of bias in one or more domains. If the trials were non-blinded, we considered them as at high risk of bias for performance bias and detection bias but only for outcomes other than overall survival.

We resolved any differences in opinion by discussion. We consulted a third author (OA) to arbitrate decisions when necessary.

\section{Assessment of bias in conducting the systematic review}

We conducted the review according to our published protocol (Abdel-Rahman 2017b). 


\section{Measures of treatment effect}

We entered the outcome data for each study into the data tables in Review Manager 5.3 to calculate the treatment effects (RevMan 2014). We used risk ratio for dichotomous outcomes, and mean differences or standardised mean differences for continuous outcomes. We also used hazard ratios as a measure of effect for time-to-event outcomes (overall survival).

We planned to undertake meta-analyses only where this is meaningful, i.e. if the treatments, participants and the underlying clinical question were similar enough for pooling to make sense.

\section{Dealing with missing data}

We contacted investigators to verify key study characteristics and obtain missing numerical outcome data where possible (e.g. when a study was identified only as an abstract). Where this was not possible, and the missing data were thought to introduce serious bias, we explored the impact of including such studies in the overall assessment of results by conducting a sensitivity analysis.

If numerical outcome data were missing, such as standard deviations or correlation coefficients, and they could not be obtained from the trial authors, we planned to calculate these from other available statistics such as $P$ values, according to the methods described in the Cochrane Handbook for Systematic Reviews of Interventions (Higgins 2011).

\section{Assessment of heterogeneity}

We planned to use the $\mathrm{Chi}^{2}$ test to assess heterogeneity. We also planned to use the $1^{2}$ statistic to quantify heterogeneity, and would have considered values greater than or equal to $50 \%$ as representing substantial heterogeneity, which we would have investigated further in subgroup analyses (Higgins 2002).

\section{Assessment of reporting biases}

Had we been able to pool more than 10 trials, we planned to create and examine a funnel plot to explore possible small-study and publication biases (Egger 1997; Macaskill 2001).

\section{Data synthesis}

We planned to pool data from studies we judged to be clinically homogeneous using Review Manager 5.3 software (RevMan 2014). If more than one study provided usable data in any single comparison, we planned to perform a meta-analysis.

\section{GRADE and 'Summary of findings' table}

We created two narrative 'Summary of findings' tables using the following outcomes: median overall survival, health-related health-related quality of life, adverse events, progression-free survival, postoperative complications and treatment-related death (Summary of findings for the main comparison; Summary of findings 2). For adverse events, we used a summary end point (total risk for all serious adverse events). We used the five GRADE considerations (study limitations, consistency of effect, imprecision, indirectness and publication bias) to assess the quality of a body of evidence as it related to the studies which contributed data to the meta-analyses for the prespecified outcomes. We used methods and recommendations described in Section 8.5 and Chapter 12 of the Cochrane Handbook (Higgins 2011) using GRADEpro GDT software (GRADEpro GDT 2014). We justified all decisions to downgrade or upgrade the quality of studies using footnotes, and we made comments to aid the reader's understanding of the review where necessary.

\section{Subgroup analysis and investigation of heterogeneity}

Where possible, we planned to conduct subgroup analyses to evaluate the effect of the intervention for each of the following groups:

- Eastern Cooperative Oncology Group (ECOG) Performance Status of 0 ("fully active, able to carry on all pre-disease performance without restriction") to 1 ("restricted in physically strenuous activity but ambulatory and able to carry out work of a light or sedentary nature, e.g. light house work, office work") compared to status 2 ("ambulatory and capable of all self care but unable to carry out any work activities; up and about more than $50 \%$ of waking hours") (ECOG-ACRIN);

- Tumour stage considering the adequacy of the staging; and

- Histology (e.g. epithelioid versus sarcomatoid versus biphasic).

\section{Sensitivity analysis}

We planned to perform sensitivity analyses if significant heterogeneity among studies was found. We planned to consider the quality of the included studies when performing sensitivity analyses. We planned also to investigate the effects of intentionto-treat analysis, adequacy of allocation concealment (blinding), incomplete reporting of the review's primary outcome (HRs for death estimated from the study report or provided by the study authors). We planned to analyse trials with an overall low risk of bias compared to trials with an overall high risk of bias.

\section{RE S U L T S}

\section{Description of studies}

We identified 3844 citations from our database searches.

\section{Results of the search}

Among the identified 3844 citations, we removed 283 duplicate references. Therefore, we screened 3561 references. Based on titles and abstracts, we excluded 3555 references. Therefore, we retrieved six full-text papers (Figure 1). Based on the full papers, we found two randomised clinical trials to be eligible for our systematic review (Stahel 2016; Treasure 2011). We excluded the remaining four studies (Pass 1997; Rea 2007; Sauter 1995; Yamanaka 2009).

\section{Included studies}

We included and analysed two trials in this systematic review. The trials included a total of 104 randomised participants and both randomised participants to two treatment groups. The first trial compared extrapleural pneumonectomy (EPP) plus postoperative hemithoracic radiotherapy versus standard (nonradical) therapy alone following platinum-based chemotherapy (Treasure 2011). The second trial compared combined EPP plus neoadjuvant platinum-based chemotherapy plus postoperative high-dose hemithoracic radiotherapy versus combined EPP plus platinum-based chemotherapy (Stahel 2016).

In Treasure 2011,112 patients were registered; they underwent induction platinum-based chemotherapy. After chemotherapy, patients underwent restaging by computerised tomography (CT) 
and those who were deemed fit by the referring clinical team had their clinical data and imaging reports assessed by the virtual multidisciplinary team of the study. Only 50 patients were deemed eligible for randomisation to either the EPP arm of the trial (surgery followed by radical radiotherapy) or the arm receiving standard (non-radical) therapy alone. Twenty-four participants were randomised to the EPP arm and 26 participants were randomised to standard therapy alone. Only 16 out of the 24 participants completed EPP. Patients in the standard therapy arm received continued oncological management according to local policy, which could include further chemotherapy, palliative radiotherapy, or further surgery. This trial was essentially comparing a radical approach to a palliative approach of treatment.

This trial assessed health-related quality of life with the European Organisation for Research and Treatment of Cancer (EORTC) healthrelated quality of life assessment (EORTC QLQ-C30 and QLQ-LC13). Forty-nine participants consented to fill out the questionnaire but only 12 participants in the EPP arm and 19 participants in the noEPP arm actually completed it. Health-related quality of life scores were lower in the EPP arm but the differences between the EPP and no-EPP scores were not statistically significant. Noteworthy, 10 serious adverse effects were reported in the EPP arm and 2 in the no EPP arm

In Stahel 2016, selected patients had pathologically confirmed resectable, tumour/node/metastasis (TNM) stages T1 toT3, NO to N2, M0 malignant pleural mesothelioma; World Health Organization (WHO) performance status 0 to 1 ; age 18 to 70 years. One hundred and fifty-one patients were selected to receive neoadjuvant chemotherapy (of whom only 145 completed chemotherapy). Only 113 patients had EPP. All 151 patients were assessed for efficacy and safety and 99 patients were eligible to proceed to part 2. Forty-five out of the 99 were excluded and then 27 participants were randomised to the radiotherapy arm and another 27 to the no-radiotherapy arm. This trial was comparing two different radical (potentially curative) approaches of treatment.

In Stahel 2016, health-related quality of life was assessed by standardised telephone interviews using the Rotterdam Symptom Checklist. They recorded no changes in the scores for the overall evaluation of life up to week 14 after randomisation.
It has to be noted that both trials were very small ( 54 patients in Stahel 2016 and 50 patients in Treasure 2011) and neither study was powered to show a clinically relevant difference in overall survival. Stahel 2016 was the second, randomised, part of a phase-2 study; while Treasure 2011 was a feasibility study to see if a larger definitive RCT was possible.

\section{Excluded studies}

We excluded four studies as they did not fulfil our inclusion criteria. One of the excluded studies did not fit into any of the combinations of therapy predefined previously in the protocol of this review (Pass 1997). Three other studies were excluded because they were nonrandomised (Sauter 1995; Rea 2007; Yamanaka 2009).

\section{Ongoing studies:}

We found three ongoing randomised trials evaluating radical multimodality strategies for MPM and their results are awaited (NCT02040272; NCT02153229; NCT02436733). One ongoing randomised trial is evaluating the benefit of chemotherapy followed by pleurectomy/decortication $(P / D)$ versus no $P / D$ in patients with MPM (NCT02040272). Another ongoing randomised trial is evaluating $P / D$ and postoperative chemotherapy with or without intraoperative porfimer sodium-mediated photodynamic therapy (NCT02153229). A third ongoing randomised trial is evaluating $P / D$ preceded or followed by chemotherapy in patients with early-stage MPM (NCT02436733). These trials may cast light on the alternative surgical procedure for MPM (which is $P / D$ ) which was not evaluated in the included two trials of this review (Characteristics of ongoing studies). We found these studies after we conducted a search of ClinicalTrials.gov (www.ClinicalTrials.gov) and the World Health Organization (WHO) trials portal (http://apps.who.int/trialsearch/).

\section{Risk of bias in included studies}

Two review authors independently assessed the risk of bias of the included trials according to the criteria outlined in the Cochrane Handbook for Systematic Reviews of Interventions (Higgins 2011) and there was no disagreement on the assessment of risk of bias in included trials. For graphical presentations of our 'Risk of bias' assessments across the included trials, see Figure 2 and Figure 3. 
Figure 2. Risk of bias summary: review authors' judgements about each 'Risk of bias' item for each included study (the judgement for performance and detection bias is for endpoints other than overall survival).

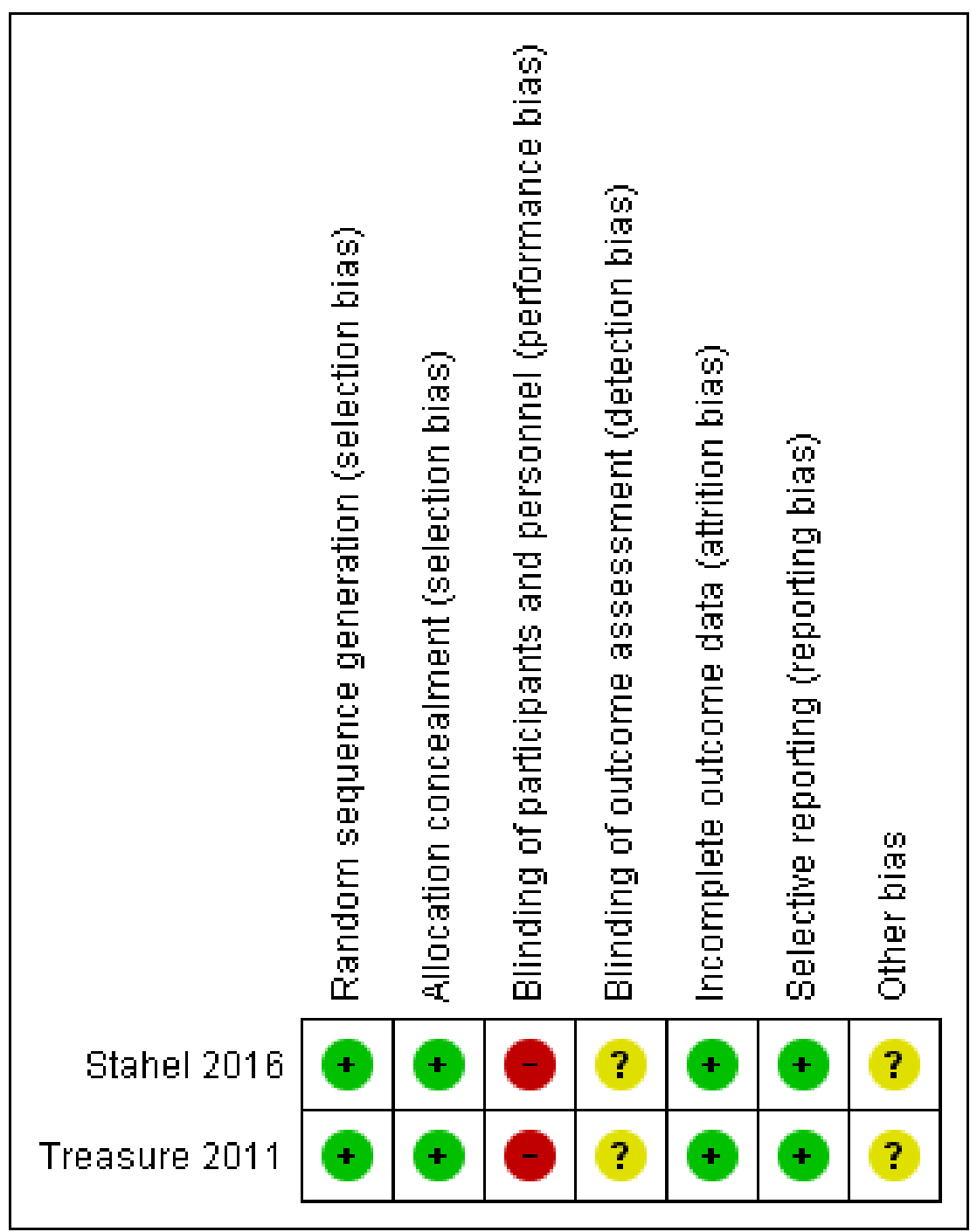


Figure 3. Risk of bias graph: review authors' judgements about each 'Risk of bias' item presented as percentages across all included studies (the judgement for performance and detection bias is for endpoints other than overall survival).

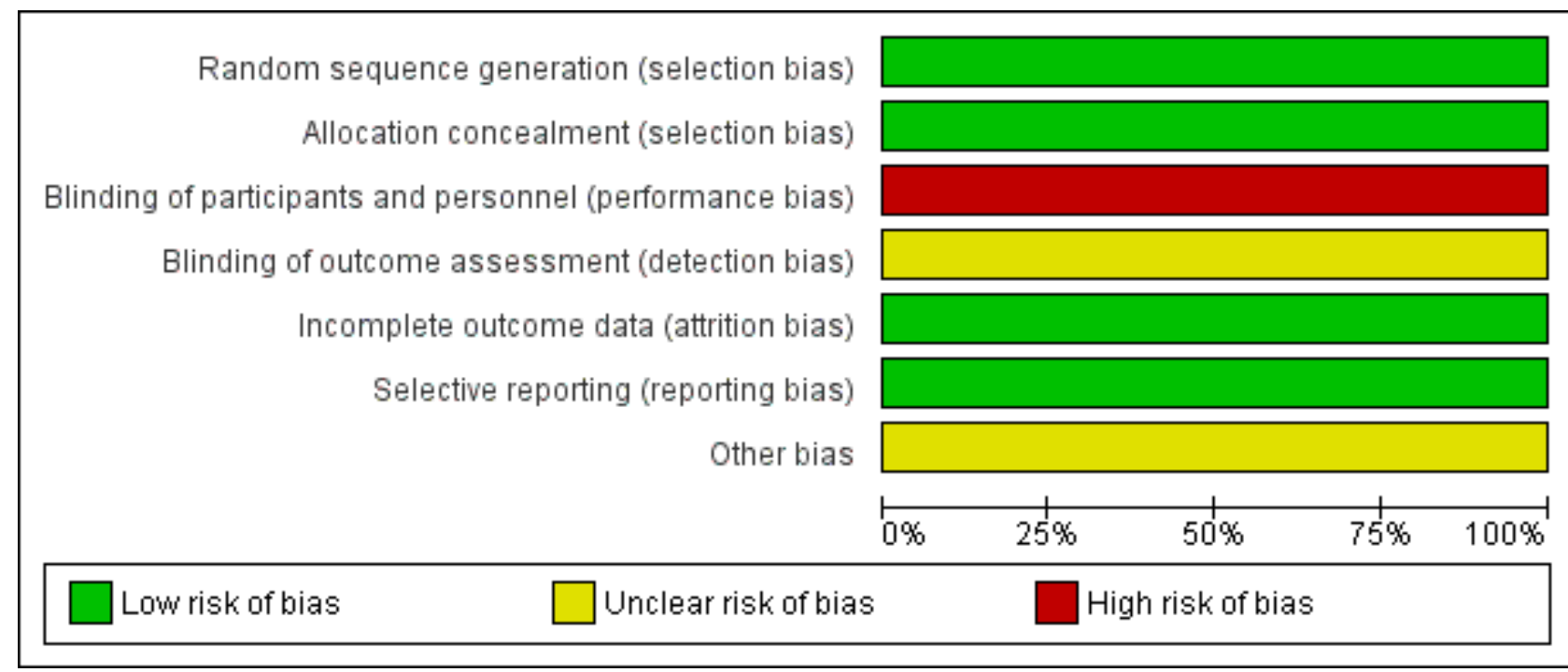

\section{Allocation}

We judged both trials to have low risk of selection bias as the generation of the random sequence was clearly reported in both trials and the randomisation was done using computer-generated sequence.

\section{Blinding}

We deemed both trials to have a high risk of performance bias because neither participants nor personnel were masked to treatment allocation (we note that tested interventions like radiotherapy or surgery cannot practically be blinded and there can be no placebo for surgery or radiotherapy). We assessed both trials as having an unclear risk of detection bias. It has to be noted however that for the endpoint of overall survival, this may not be considered as high risk for either performance or detection bias.

\section{Incomplete outcome data}

We judged both trials to be at low risk of attrition bias. In Stahel 2016, there were no missing data in the study; while in Treasure 2011, the published analysis included summary information from the screening logs on reasons for loss and withdrawal.

\section{Selective reporting}

Because reporting bias was detected in neither study, we considered the risk of reporting bias as low in both trials.

\section{Other potential sources of bias}

We could not detect any other potential sources of bias in either study and so we judged the risk of other biases as low.

\section{Effects of interventions}

See: Summary of findings for the main comparison; Summary of findings 2

We initially planned to conduct a meta-analysis; however, because the treatments, participants and the underlying clinical question were not similar enough for pooling to make sense, we did not conduct a meta-analysis for the included two trials.

\section{Primary outcomes}

\section{Overall survival}

For Treasure 2011 the overall survival was worse in the radical treatment arm: the median overall survival from randomisation for participants allocated to extrapleural pneumonectomy (EPP) was 14.4 months (95\% confidence interval (CI) 5.3 to 18.7). For participants randomised to no EPP, median survival was estimated to be 19.5 months ( $95 \% \mathrm{Cl} 13.4$ to time not-yet-reached). The hazard ratio for overall survival in the EPP group (unadjusted) versus the no-EPP group was $1.90(95 \% \mathrm{Cl} 0.92$ to 3.93; $\mathrm{P}=0.082)$. After adjustment for prespecified prognostic factors, the HR was 2.75 (1.21 to $6.26 ; P=0.016$ ).

For Stahel 2016, median overall survival calculated from registration was 20.8 months $(95 \% \mathrm{Cl} 14.4$ to 27.8$)$ in the noradiotherapy group and 19.3 months $(95 \% \mathrm{Cl} 11.5$ to 21.8$)$ in the radiotherapy group.

\section{Health-related quality of life}

For Treasure 2011, there were no statistically significant differences in median quality-of-life scores between both treatment groups.

For Stahel 2016, psychological and physical symptom distress and activity level impairment was improved over time in participants not receiving radiotherapy. Participants receiving radiotherapy reported rather stable scores in these domains, except for activity level, which worsened up to four weeks after randomisation but recovered to baseline scores thereafter. The authors recorded no changes in the scores for the overall evaluation of life in both groups up to week 14 after randomisation. 


\section{Adverse events}

In Treasure 2011, 12 serious adverse events were reported during the study period: ten in the EPP group and two in the no-EPP group. Details of these serious adverse events were not available.

In Stahel 2016, the following adverse events were observed in the radiotherapy arm: anaemia (74\%), nausea or vomiting $(44 \%)$, oesophagitis (29\%), fatigue (24\%), weight loss (19\%), dyspnoea (4\%), diarrhoea (4\%), and increased alkaline phosphatase concentration (4\%). There was no comment on the adverse events in the no-radiotherapy arm.

\section{Secondary outcomes}

\section{Progression-free survival}

In Treasure 2011, median recurrence-free survival in the EPP group was 7.6 months $(95 \% \mathrm{Cl} 5.0$ to 13.4$)$ and median progression-free survival in the no-EPP group was estimated to be 9.0 months ( $95 \%$ $\mathrm{Cl} 7.2$ to 14.7$)$.

In Stahel 2016, median locoregional relapse-free survival (a subset of progression-free survival) from surgery, was 7.6 months $(95 \% \mathrm{Cl}$ 4.5 to 10.7 ) in the no-radiotherapy group and 9.4 months (6.5 to $11.9)$ in the radiotherapy group.

\section{Postoperative complications}

In Treasure 2011, postoperative complications included two incidents of reoperation, five cardiac complications, four pulmonary complications and one incident of urine retention.

In Stahel 2016, postoperative complications included mediastinal shift (11\%), major infections (8\%), bleeding (6\%), bronchial stump fistula (3\%), pulmonary embolism, chylothorax, and technical failures ( $2 \%$ each).

\section{Treatment-related deaths}

In Treasure 2011, three perioperative deaths occurred in patients randomly assigned to EPP: one had a rupture of the aortic isthmus (multiple sites) and died on the operating table; one died at home (cause unknown) shortly after a further operation to have a diaphragm patch repaired; and one died of bronchopneumonia six weeks after the EPP operation. One perioperative death occurred in the no-EPP group because one of the patients underwent EPP surgery outside the trial and the patient died of multiple organ failure.

In Stahel 2016, one patient died of a complicated pneumonia during radiotherapy, which was probably related to treatment.

\section{Locoregional and distant recurrence rates}

Neither of the two trials reported on locoregional or distant recurrence rates.

\section{DISCUSSION}

\section{Summary of main results}

On the basis of one randomised clinical trial (Stahel 2016) comparing combined extrapleural pneumonectomy (EPP) plus neoadjuvant platinum-based chemotherapy plus postoperative high-dose hemithoracic radiotherapy with combined EPP plus platinum-based chemotherapy, postoperative hemithoracic radiotherapy does not appear to confer survival or quality-oflife advantages. Moreover, it is likely to be associated with more adverse events. On the basis of another randomised clinical trial comparing EPP plus postoperative hemithoracic radiotherapy with standard (non-radical) therapy alone following platinumbased chemotherapy (where patients in the standard therapy arm received continued oncological management according to local policy) (Treasure 2011), the addition of EPP and postoperative hemithoracic radiotherapy results in more adverse events and does not appear to improve survival. Treasure 2011 showed that there might in fact be an adverse effect on survival from the more radical treatment approach. The median overall survival in both arms of Stahel 2016 was about 20 months from registration, while in Treasure 2011 the median survival of participants in the no-EPP/radiotherapy group was 19.5 months from randomisation, with a median of 3.6 months from registration to randomisation, and median overall survival from randomisation for participants allocated to EPP was 14.4 months. This raises the possibility that adding radical surgery plus radiotherapy may result in worse survival outcomes compared to giving chemotherapy alone.

However, both trials were very small (54 patients for Stahel 2016 and 50 patients for Treasure 2011) and neither was powered to show a clinically relevant difference in overall survival. This indicates the difficulty of recruiting patients into these kinds of trials. Moroever, there is an important difference in the intention of the two trials: while Treasure 2011 was essentially comparing a radical to a palliative approach of treatment, Stahel 2016 compared two different radical approaches of treatment. Additionally, it has to be noted that among the 24 participants assigned to EPP/hemithoracic radiotherapy in Treasure 2011 study, only 16 participants completed EPP.

These two trials were set up in the context of a widespread belief in the potential benefit of EPP/radiotherapy in malignant pleural mesothelioma (MPM), based on some observational studies with strong selection bias (Taioli 2015). However, following the publication of Treasure 2011, an important question arose about whether or not a radical surgical approach is really justified in MPM management. It is worth noting here that Treasure 2011 trial was a feasibility study; but it did not lead to the development of a larger, more definitive study. Possibly, a trend for a poorer survival and higher adverse events (although not statistically significant) was enough to discourage people from pursuing a larger trial.

We found three ongoing randomised trials evaluating radical multimodality strategies for MPM and their results are awaited (NCT02040272; NCT02153229; NCT02436733).

\section{Overall completeness and applicability of evidence}

We could not find evidence covering all the main comparisons included in the objective. No definite conclusions can be made about survival and health-related quality of life given the moderate to low quality of evidence level.

\section{Quality of the evidence}

We assessed the overall evidence as moderate quality (for the outcome of overall survival) and as low quality (for other outcomes) using the GRADE approach. This is because of the high risk of bias (for outcomes other than overall survival), and imprecision. Generation of the random sequence was clearly reported in both 
trials. The allocation concealment in both trials was of low risk of bias. There was high risk of performance bias in both trials (for outcomes other than overall survival); while detection bias was unclearly reported in both trials. There was low risk of reporting and attrition biases in both trials. There was a high risk of for profit bias in Stahel 2016 and low risk of for profit bias in Treasure 2011.

\section{Potential biases in the review process}

Publication bias might be an issue; however, due to the fact we could only include two trials in this review, we were unable to assess this formally.

\section{Agreements and disagreements with other studies or reviews}

We found one systematic review evaluating trimodality therapy (EPP, chemotherapy and adjuvant radiotherapy) for patients with MPM (Cao 2012). Selection criteria for that systematic review differed from the present systematic review (the authors did not restrict the inclusion to randomised controlled trials like we did). There was only one randomised trial among the 16 studies included in Cao 2012; this trial was also included in our systematic review (Treasure 2011). Median overall survival in Cao 2012 ranged from 12.8 to 46.9 months. Disease-free survival ranged from 10 to 16.3 months and perioperative mortality ranged from $0 \%$ to $12.5 \%$. The authors of Cao 2012 reached the conclusion that outcomes of patients who underwent trimodality therapy appeared to be inconsistent. Their conclusion cannot be compared to our conclusion because of the difference in inclusion criteria between the two reviews.

\section{AUTHORS' CONCLUSIONS}

\section{Implications for practice}

The overall strength of the evidence gathered in this review is low and there is a lack of available evidence to support the use of radical multimodality therapy in routine clinical practice (particularly as one trial suggests greater harm). Given the added cost of multimodality treatment and the possible increase in risk of adverse effects, the lack of evidence of their effectiveness probably means that these interventions should currently be limited to clinical trials alone.

\section{Implications for research}

There is a need for good quality, large, randomised clinical trials of radical multimodality therapy for MPM. It is important that the randomisation process is clearly described, as well as the interventions. The participant flow should be well-specified, as should data handling. Recruitment to these types of trials that include surgery is quite difficult; and so multicenter/multinational collaboration is preferred. These trials may provide evidence to draw conclusions about the survival and the health-related quality of life of MPM patients treated with multimodality therapy. Also, they may provide a larger sample size for use in pooled analyses. Currently ongoing mesothelioma trials are using surgery less radical than EPP; a possible reason for this is the discouraging survival results (combined with extra-morbidity) that were observed in Treasure 2011 study. It is not thus expected to explore EPP in upcoming randomised trials in the near future.

\section{ACKN OWLEDGEMENTS}

We would like to thank the Cochrane Lung Cancer group and its supporting editorial team.

Editors: Fergus Macbeth, Renée Manser, Arnaud Scherpereel, Alain Bernard and Virginie Westeel

Managing editor: Corynne Marchal

Information specialists: François Calais, Giorgio Maria Agazzi 


\section{RE F E R E N C E S}

\section{References to studies included in this review}

Stahel 2016 \{published data only\}

Stahel R A, Riesterer O, Xyrafas A, Opitz I, Beyeler M, Ochsenbein A, et al. Neoadjuvant chemotherapy and extrapleural pneumonectomy of malignant pleural mesothelioma with or without hemithoracic radiotherapy (SAKK 17/04): a randomised, international, multicentre phase 2 trial. Lancet Oncology 2016; Vol. 16:1651-8.

\section{Treasure 2011 \{published data only\}}

Treasure T, Lang-Lazdunski L, Waller D, Bliss J M, Tan C, Entwisle J, et al. Extra-pleural pneumonectomy versus no extrapleural pneumonectomy for patients with malignant pleural mesothelioma: clinical outcomes of the Mesothelioma and Radical Surgery (MARS) randomised feasibility study. Lancet Oncology 2011;12:763-72.

\section{References to studies excluded from this review}

Pass 1997 \{published data only\}

Pass HI, Temeck BK, Kranda K, Thomas G, Russo A, Smith P, et al. Phase III randomized trial of surgery with or without intraoperative photodynamic therapy and postoperative immunochemotherapy for malignant pleural mesothelioma. Annals of surgical oncology: the official journal of the Society of Surgical Oncology 1997;4:628-33.

\section{Rea 2007 \{published data only\}}

Rea F, Marulli G, Bortolotti L, Breda C, Favaretto A G, Loreggian L, et al. Induction chemotherapy, extrapleural pneumonectomy (EPP) and adjuvant hemi-thoracic radiation in malignant pleural mesothelioma (MPM): Feasibility and results. Lung Cancer 2007;57:89-95.

\section{Sauter 1995 \{published data only\}}

Sauter ER, Langer C, Coia LR, Goldberg M, Keller SM. Optimal management of malignant mesothelioma after subtotal pleurectomy: revisiting the role of intrapleural chemotherapy and postoperative radiation. Journal of Surgical Oncology 1995;60:100-5

\section{Yamanaka 2009 \{published data only\}}

Yamanaka T, Tanaka F, Hasegawa S, Okada M, Soejima T, Kamikonya N, et al. A feasibility study of induction pemetrexed plus cisplatin followed by extrapleural pneumonectomy and postoperative hemithoracic radiation for malignant pleural mesothelioma. Japanese Journal of Clinical Oncology 2009;39:186-8.

\section{References to ongoing studies}

NCT02040272 \{published data only\}

NCT02040272. MARS 2: a feasibility study comparing (extended) pleurectomy decortication versus no pleurectomy decortication in patients With malignant pleural mesothelioma (MARS2) [A study to determine if it is feasible to recruit into a randomised trial comparing (extended) pleurectomy decortication versus no pleurectomy decortication in patients with malignant pleural mesothelioma]. clinicaltrials.gov/ct2/show/NCT02040272 (first received 20 December 2013).

NCT02153229 \{published data only\}

NCT02153229. MPM PDT phase II trial [A randomized phase 2 trial of radical pleurectomy and post-operative chemotherapy with or without intraoperative porfimer sodium -mediated photodynamic therapy for patients with epitheliod malignant pleural mesothelioma]. clinicaltrials.gov/ct2/show/ NCT02153229 (first received 28 May 2014).

\section{NCT02436733 \{published data only\}}

NCT02436733. Pleurectomy/ Decortication (P/D) preceded or followed by chemotherapy in patients with early stage MPM [EORTC randomized phase II study of pleurectomy/ decortication (P/D) preceded or followed by chemotherapy in patients with early stage malignant pleural mesothelioma]. clinicaltrials.gov/ct2/show/NCT02436733 (first received 21 April 2015).

\section{Additional references}

\section{Abdel-Rahman 2015}

Abdel-Rahman O, Kelany M. Systemic therapy options for malignant pleural mesothelioma beyond first-line therapy: a systematic review. Expert Review of Respiratory Medicine 2015;9(5):533-49.

\section{Abdel-Rahman 2017a}

Abdel-Rahman $\mathrm{O}$. Role of postoperative radiotherapy in the management of malignant pleural mesothelioma: A propensity score matching of the SEER database. Strahlentherapie und Onkologie 2017 Jan 2 [Epub ahead of print]. [DOI: 10.1007/ s00066-016-1092-7]

\section{Abdel-Rahman 2017b}

Abdel-Rahman O, Elsayed Z, Mohamed H, Eltobgy M. Radical multimodality therapy for malignant pleural mesothelioma. Cochrane Database of Systematic Reviews 2017, Issue 3. [DOI: 10.1002/14651858.CD012605]

\section{Abdel-Rahman 2017c}

Abdel-Rahman O. Challenging a dogma; AJCC 8th staging system is not sufficient to predict outcomes of patients with malignant pleural mesothelioma. Lung Cancer 2017;113:128-33.

\section{Algranti 2015}

Algranti E, Saito CA, Carneiro AP, Moreira B, Mendonca EM, Bussacos MA. The next mesothelioma wave: mortality trends and forecast to 2030 in Brazil. Cancer Epidemiology 2015;39(5):687-92.

\section{Allen 2006}

Allen A M, Czerminska M, Janne P A, Sugarbaker D J, Bueno R, Harris J R, et al. Fatal pneumonitis associated with intensity-modulated radiation therapy for mesothelioma. 
International Journal of Radiation, Oncology, Biology and Physics 2006;65(3):640-5.

\section{Armato 2013}

Armato SG 3rd, Labby ZE, Coolen J, Klabatsa A, Feigen M, Persigehl T, et al. Imaging in pleural mesothelioma: a review of the 11th International Conference of the International Mesothelioma Interest Group. Lung Cancer 2013;82(2):190-6.

\section{Baas 2015}

Baas P, Fennell D, Kerr KM, Van Schil PE, Haas RL, Peters S. ESMO Guidelines Committee. Malignant pleural mesothelioma: ESMO Clinical Practice Guidelines for diagnosis, treatment and follow-up. Annals of Oncology 2015;26(Suppl 5):v31-9.

\section{Bertoglio 2016}

Bertoglio $\mathrm{P}$, Waller DA. The role of thoracic surgery in the management of mesothelioma: an expert opinion on the limited evidence. Expert Review of Respiratory Medicine 2016;10(6):663-72.

\section{Bianchi 2007}

Bianchi C, Bianchi T. Malignant mesothelioma: global incidence and relationship with asbestos. Industrial Health 2007;45(3):379-87.

\section{Bridda 2007}

Bridda A, Padoan I, Mencarelli R, Frego M. Peritoneal mesothelioma: a review. Medscape General Medicine 2007;9(2):32.

\section{Brčić 2014}

Brčić L, Jakopović M, Brčić I, Klarić V, Milošević M, Sepac A, et al. Reproducibility of histological subtyping of malignant pleural mesothelioma. Virchows Archives 2014;465(6):679-85.

\section{Calabro 2013}

Calabro L, Morra A, Fonsatti E, Cutaia O, Amato G, Giannarelli D, et al. Tremelimumab for patients with chemotherapy-resistant advanced malignant mesothelioma: an open-label, single-arm, phase 2 trial. Lancet Oncology 2013;14(11):1104-11.

\section{Calabro 2015}

Calabro L, Morra A, Fonsatti E, Cutaia O, Fazio C, Annesi D, et al. Efficacy and safety of an intensified schedule of tremelimumab for chemotherapy-resistant malignant mesothelioma: an openlabel, single-arm, phase 2 study. Lancet Respiratory Medicine 2015;3(4):301-9.

\section{Cao 2012}

Cao C, Tian D, Manganas C, Matthews P, Yan TD. Systematic review of trimodality therapy for patients with malignant pleural mesothelioma. Annals of cardiothoracic surgery 2012;1(4):428-37.

\section{Chapman 2006}

Chapman E, García Diéguez M. Radiotherapy for malignant pleural mesothelioma. Cochrane Database of Systematic Reviews 2006, Issue 3. [DOI: 10.1002/14651858.CD003880.pub4]

\section{CTCAE 2009}

US Department of Health and Human Services. Common terminology criteria of adverse events (CTCAE). Version 4.03. evs.nci.nih.gov/ftp1/CTCAE/CTCAE_4.03_2010-06-14_ QuickReference_5x7.pdf Accessed prior to 27 February 2017.

\section{De Perrot 2016}

De Perrot M, Feld R, Leighl NB, Hope A, Waddell TK, Keshavjee S, et al. Accelerated hemithoracic radiation followed by extrapleural pneumonectomy for malignant pleural mesothelioma. Journal of Thoracic and Cardiovascular Surgery 2016;151(2):468-73.

\section{Eastment 2017}

Eastment J, Burke J, Fong K, Yang I, Bowman R. Radiation therapy for preventing instrumentation track metastases in malignant pleural mesothelioma. Cochrane Database of Systematic Reviews 2017, Issue 2. [DOI: 10.1002/14651858.CD012541]

\section{Egger 1997}

Egger M, Smith GD, Phillips AN. Meta-analysis: principles and procedures. British Medical Journal 1997;315(7121):1533-7.

\section{Flores 2008}

Flores RM, Pass HI, Seshan VE, Dycoco J, Zakowski M, Carbone $\mathrm{M}$, et al. Extrapleural pneumonectomy versus pleurectomy/decortication in the surgical management of malignant pleural mesothelioma: results in 663 patients. The Journal of Thoracic and Cardiovascular Surgery 2008;135(3):620-6, 6.

\section{Friedberg 2012}

Friedberg JS. Photodynamic therapy for malignant pleural mesothelioma. Journal of the National Cancer Institute 2012;10(Suppl 2):S75-9.

\section{Friedberg 2017}

Friedberg JS, Simone CB 2nd, Culligan MJ, Barsky AR, Doucette A, McNulty S, et al. Extended pleurectomydecortication-based treatment for advanced stage epithelial mesothelioma yielding a median survival of nearly three years. Annals of Thoracic Surgery 2017;103(3):912-9.

\section{Galateau-Salle 2016}

Galateau-Salle F, Churg A, Roggli V, Travis WD. World Health Organization Committee for Tumors of the Pleura. The 2015 World Health Organization Classification of Tumors of the Pleura: Advances since the 2004 classification. Journal of Thoracic Oncology 2016;11(2):142-54.

\section{GRADEpro GDT 2014 [Computer program]}

GRADE Working Group, McMaster University. GRADEpro GDT. Version Accessed prior to 27 February 2017. Hamilton (ON): GRADE Working Group, McMaster University, 2014.

\section{Heelan 1999}

Heelan RT, Rusch VW, Begg CB, Panicek DM, Caravelli JF, Eisen C. Staging of malignant pleural mesothelioma: comparison of CT and MR imaging. American Journal of Roentgenology 1999;172(4):1039-47. 


\section{Hiddinga 2013}

Hiddinga BI, van Meerbeeck JP. Surgery in mesothelioma-where do we go after MARS?. Journal of Thoracic Oncology 2013;8(5):525-9.

\section{Higgins 2002}

Higgins JP, Thompson SG. Quantifying heterogeneity in a metaanalysis. Statistics in Medicine 2002;21(11):1539-58.

\section{Higgins 2011}

Higgins JPT, Green S (editors). Cochrane Handbook for Systematic Reviews of Interventions Version 5.1.0. The Cochrane Collaboration, 2011.Available from www.cochranehandbook.org, [updated March 2011].

\section{Kadota 2011}

Kadota K, Suzuki K, Sima CS, Rusch VW, Adusumilli PS, Travis WD. Pleomorphic epithelioid diffuse malignant pleural mesothelioma: a clinicopathological review and conceptual proposal to reclassify as biphasic or sarcomatoid mesothelioma. Journal of Thoracic Oncology 2011;6(5):896-904.

\section{Macaskill 2001}

Macaskill P, Walter S D, Irwig L. A comparison of methods to detect publication bias in meta-analysis. Statistics in Medicine 2001;20:641-54.

\section{Macleod 2014}

Macleod N, Price A, O'Rourke N, Fallon M, Laird B. Radiotherapy for the treatment of pain in malignant pleural mesothelioma: a systematic review. Lung Cancer 2014;83(2):133-8.

\section{MacLeod 2015}

MacLeod N, Chalmers A, O'Rourke N, Moore K, Sheridan J, McMahon L, et al. Is radiotherapy useful for treating pain in mesothelioma?: A phase II trial. Journal of Thoracic Oncology 2015;10(6):944-50.

\section{Manegold 2003}

Manegold C. Pemetrexed (Alimta, MTA, multitargeted antifolate, LY231514) for malignant pleural mesothelioma. Seminars in Oncology 2003;30(4 Suppl 10):32-6.

\section{Mohamed 2017}

Mohamed H, Eltobgy M, Abdel-Rahman O. Immune checkpoints aberrations and malignant mesothelioma: Assessment of prognostic value and evaluation of therapeutic potentials. Anticancer Agents in Medicinal Chemistry 2017 Jan 2 [Epub ahead of print].

\section{Moher 2009}

Moher D, Liberati A, Tetzlaff J, Altman DG. Preferred reporting items for systematic reviews and meta-analyses: the PRISMA statement. PLoS Med 2009;6(7):e1000097.

\section{Mott 2012}

Mott FE. Mesothelioma: a review. The Ochsner Journal 2012;12(1):70-9.

\section{Pruefer 2008}

Pruefer FG, Lizarraga F, Maldonado V, Melendez-Zajgla J. Participation of Omi Htra2 serine-protease activity in the apoptosis induced by cisplatin on SW480 colon cancer cells. Journal of Chemotherapy 2008;20(3):348-54.

\section{RevMan 2014 [Computer program]}

Copenhagen: The Nordic Cochrane Centre,The Cochrane Collaboration. Review Manager (RevMan).Version 5.3. Copenhagen: The Nordic Cochrane Centre,The Cochrane Collaboration, 2014.

\section{Robinson 2012}

Robinson BM. Malignant pleural mesothelioma: an epidemiological perspective. Annals of Cardiothoracic Surgery 2012; Vol. 1, issue 4:491-6.

\section{Runxiao 2016}

Runxiao L, Yankun C, Lan W. A pilot study of volumetricmodulated arc therapy for malignant pleural mesothelioma. Journal of Applied Clinical Medical Physics 2016;17(2):5980.

\section{Rusch 2001}

Rusch VW, Rosenzweig K, Venkatraman E, Leon L, Raben A, Harrison L, et al. A phase II trial of surgical resection and adjuvant high-dose hemithoracic radiation for malignant pleural mesothelioma. Journal of Thoracic and Cardiovascular surgery 2001; Vol. 122, issue 4:788-95.

\section{Rusch 2016}

Rusch VW, Chansky K, Kindler HL, Nowak AK, Pass HI, Rice DC, et al. The IASLC Mesothelioma Staging Project: Proposals for the M Descriptors and for Revision of the TNM Stage Groupings in the Forthcoming (Eighth) Edition of the TNM Classification for Mesothelioma. Journal of Thoracic Oncology 2016;11(12):2112-9.

\section{Saini 2016}

Saini R, Lee NV, Liu KY, Poh CF. Prospects in the application of photodynamic therapy in oral cancer and premalignant lesions. Cancers 2016;8(9):83-6.

\section{Scherpereel 2010}

Scherpereel A, Astoul P, Baas P, Berghmans T, Clayson H, de Vuyst $P$, et al. Guidelines of the European Respiratory Society and the European Society of Thoracic Surgeons for the management of malignant pleural mesothelioma. European Respiratory Journal 2010;35(3):479-95.

\section{Schipper 2008}

Schipper PH, Nichols FC, Thomse KM, Deschamps C, Cassivi SD, Allen MS, et al. Malignant pleural mesothelioma: surgical management in 285 patients. Ann Thorac Surg 2008;85(1):257-64; discussion 64.

\section{Sugarbaker 1999}

Sugarbaker DJ, Flores RM, Jaklitsch MT, Richards WG, Strauss GM, Corson JM, et al. Resection margins, extrapleural nodal status, and cell type determine postoperative longterm survival in trimodality therapy of malignant pleural 
mesothelioma: results in 183 patients. Journal of Thoracic and Cardiovascular Surgery 1999;117(1):54-63; 63-5.

\section{Taioli 2015}

Taioli E, Wolf AS, Camacho-Rivera M, Kaufman A, Lee DS, Nicastri D, et al. Determinants of Survival in Malignant Pleural Mesothelioma: A Surveillance, Epidemiology, and End Results (SEER) Study of 14,228 Patients. PLoS One 2015;10(12):e0145039.

\section{Testa 2011}

Testa JR, Cheung M, Pei J, Below JE, Tan Y, Sementino E, et al. Germline BAP1 mutations predispose to malignant mesothelioma. Nature Genetics 2011;43(10):1022-5.

\section{Van Meerbeeck 2011}

Van Meerbeeck JP, Scherpereel A, Surmont VF, Baas P. Malignant pleural mesothelioma: the standard of care and challenges for future management. Critical reviews in Hematology/Oncology 2011; Vol. 78, issue 2:92-111.

\section{Van Schil 2010}

Van Schil PE, Baas P, Gaafar R, Maat AP, Van de Pol M, Hasan B, et al. European Organisation for Research and Treatment of Cancer (EORTC) Lung Cancer Group. Trimodality therapy for malignant pleural mesothelioma: results from an EORTC phase
II multicentre trial. European Respiratory Journal 2010; Vol. 36, issue 6:1362-9.

\section{Vogelzang 2003}

Vogelzang NJ, Rusthoven JJ, Symanowski J, Denham C, Kaukel E, Ruffie P, et al. Phase III study of pemetrexed in combination with cisplatin versus cisplatin alone in patients with malignant pleural mesothelioma. Journal of Clinical Oncology 2003;21(14):2636-44.

\section{Weder 2012}

Weder W, Opitz I. Multimodality therapy for malignant pleural mesothelioma. Annals of Cardiothoracic Surgery 2012;1(4):502-7.

\section{Wolchok 2013}

Wolchok JD, Hodi FS, Weber JS, Allison JP, Urba WJ, Robert C, et al. Development of ipilimumab: a novel immunotherapeutic approach for the treatment of advanced melanoma. Annals of the New York Academy of Sciences 2013;1291:1-13.

\section{Zalcman 2016}

Zalcman G, Mazieres J, Margery J, Greillier L, Audigier-Valette C, Moro-Sibilot $\mathrm{D}$, et al. Bevacizumab for newly diagnosed pleural mesothelioma in the Mesothelioma Avastin Cisplatin Pemetrexed Study (MAPS): a randomised, controlled, openlabel, phase 3 trial. Lancet 2016;387(10026):1405-14.

\section{CHARACTERISTICS OF STUDIES}

Characteristics of included studies [ordered by study ID]

Stahel 2016

Methods Randomised clinical trial with two arms: postoperative hemithoracic high-dose radiotherapy versus no postoperative radiotherapy

Participants

54 patients with pathologically confirmed mesothelioma underwent three cycles of neoadjuvant chemotherapy (cisplatin $75 \mathrm{mg} / \mathrm{m}^{2}$ and pemetrexed $500 \mathrm{mg} / \mathrm{m}^{2}$ on day 1 given every 3 weeks) and extrapleural pneumonectomy were randomly assigned (1:1), 27 in each group, to receive high-dose radiotherapy or not.

Male/female: $50 / 4$

Inclusion criteria:

- pathologically confirmed mesothelioma

- resectable TNM stages T1-3, N0-2, M0

- completion of a three cycles of neoadjuvant chemotherapy

- complete macroscopic resection (R 0-1)

- WHO performance status of 0 or 1

- age 18-70 years

- creatinine clearance of more than $60 \mathrm{~mL}$ per min

- normal haematological function, normal bilirubin and liver function

- no major organ dysfunctions, no history of other malignancies

- calculated postoperative forced expiratory volume of one second (FEV1) of greater or equal to $40 \%$ of the predicted value

Recruitment: December 2005 to October 2012 
Stahel 2016 (Continued)

Interventions
All patients had three cycles of neoadjuvant chemotherapy (cisplatin $75 \mathrm{mg} / \mathrm{m}^{2}$ and pemetrexed 500 $\mathrm{mg} / \mathrm{m}^{2}$ on day 1 given every 3 weeks).

All patients underwent extrapleural pneumonectomy with complete macroscopic resection.

Hemithoracic high-dose radiotherapy: PTV1 is the entire hemithorax, the thoracotomy channel, and mediastinal nodal stations if affected by disease or violated surgically. PTV2 are areas at high risk for loco-regional relapse.

Three dimensional conformal radio therapy or intensity modulated radiation therapy was permitted with the following schedules:

Schedule 1: 25 × 1.8 Gy (45 Gy) to PTV1 followed by 7 × 1.8 Gy (12.6 Gy) to PTV2 (57.6 Gy in total).

Schedule 2: 23 × 2 Gy (46 Gy) to PTV1 followed by $5 \times 2$ Gy (10 Gy) to PTV2 (56 Gy in total).

Schedule 3: intensity-modulated radiotherapy $26 \times 1.75$ Gy (45.5 Gy) to PTV1 with simultaneously integrated boost $26 \times 2.15 \mathrm{~Gy}(55.9 \mathrm{~Gy})$ to PTV2.

No hemithoracic high dose radiotherapy: no radiotherapy, only follow up.

Follow-up included CT scans at 4 months, 8 months, and 12 months after surgery, subsequent follow-up was done every 6 months or at time of suspicion of relapse.

\begin{tabular}{ll}
\hline Outcomes & 1. Survival rate \\
& 2. health-related quality of life \\
& 3. Adverse events \\
\hline Notes & $\begin{array}{l}\text { Funding: Swiss Group for Clinical Cancer Research, Swiss State Secretariat for Education, Research and } \\
\text { Innovation, } \\
\text { Eli Lilly. }\end{array}$
\end{tabular}

\section{Risk of bias}

\begin{tabular}{lll}
\hline Bias & Authors' judgement & Support for judgement \\
\hline $\begin{array}{ll}\text { Random sequence genera- } \\
\text { tion (selection bias) }\end{array}$ & Low risk & $\begin{array}{l}\text { Randomisation was done using computer-generated randomisation sequence } \\
\text { balanced according to centre, histology and mediastinal lymph nodes involve- } \\
\text { ment. }\end{array}$
\end{tabular}

Allocation concealment $\quad$ Low risk $\quad$ Randomisation was done using computer-generated sequence.
(selection bias)

\begin{tabular}{|c|c|c|}
\hline $\begin{array}{l}\text { Blinding of participants } \\
\text { and personnel (perfor- } \\
\text { mance bias) } \\
\text { All outcomes }\end{array}$ & High risk & $\begin{array}{l}\text { Neither participants nor personnel were masked to treatment allocation (this } \\
\text { high risk of bias was considered for endpoints other than overall survival). }\end{array}$ \\
\hline
\end{tabular}

Blinding of outcome as- Unclear risk The blinding of outcome assessors was unclear.
sessment (detection bias)
All outcomes

Incomplete outcome data Low risk No missing data in the trial.
(attrition bias)

All outcomes

Selective reporting (re- Low risk No reporting bias was detected.
porting bias)


Stahel 2016 (Continued)
Other bias
Unclear risk
There was unclear risk of other biases.

Treasure 2011

Methods Randomised clinical trial with two arms: EPP plus postoperative hemithoracic radiotherapy compared with standard (non-radical) therapy alone following platinum-based chemotherapy.

Participants patients with pathologically confirmed mesothelioma underwent induction platinum-based
chemotherapy were randomly assigned: 24 patients to EPP and 26 patients to continued oncological
management according to local policy, which could include chemotherapy, palliative radiotherapy, or
further surgery.
Mean age: 61.5 years
Male/female: $46 / 4$
Inclusion criteria:
- age: 18 years or older
- pathologically confirmed mesothelioma
- no evidence on preoperative CT staging of unresectable disease or distant metastases
- fit enough to undergo preoperative chemotherapy followed by pneumonectomy (according to British
Thoracic Society criteria for lung cancer surgery) and the planned postoperative radiotherapy

Recruitment: October 2005 to November 2008

Interventions

All patients had three cycles of platinum-based chemotherapy with a regimen chosen by the treating physician at the local centre.

EPP arm: underwent surgery, followed by postoperative radiotherapy directed at the hemithorax plus continued oncological management and follow-up and CT scan on first relapse.

No-EPP arm: only continued oncological management and follow-up and CT scan on first relapse.

\begin{tabular}{ll}
\hline Outcomes & $\begin{array}{l}\text { 1. Survival rate } \\
\text { 2. health-related quality of life }\end{array}$ \\
\hline Notes & $\begin{array}{l}\text { Funding: Cancer Research UK (CRUK/04/003), the June Hancock Mesothelioma Research Fund, and } \\
\text { Guy's and } \\
\text { St Thomas' NHS Foundation Trust. } \\
\text { We contacted the corresponding author by email (15 April 2017) for some clarifications about adverse } \\
\text { events but he could not provide the relevant information. }\end{array}$
\end{tabular}

\section{Risk of bias}

\begin{tabular}{lll}
\hline Bias & Authors' judgement & Support for judgement \\
\hline $\begin{array}{l}\text { Random sequence genera- } \\
\text { tion (selection bias) }\end{array}$ & Low risk & Randomisation was done using computer-generated randomisation sequence. \\
\hline $\begin{array}{l}\text { Allocation concealment } \\
\text { (selection bias) }\end{array}$ & Low risk & Randomisation was done using computer-generated sequence. \\
\hline $\begin{array}{l}\text { Blinding of participants } \\
\text { and personnel (perfor- } \\
\text { mance bias) }\end{array}$ & High risk & $\begin{array}{l}\text { Neither participants nor personnel were masked to treatment allocation (this } \\
\text { high risk of bias was considered for endpoints other than overall survival). }\end{array}$ \\
\end{tabular}


Treasure 2011 (Continued)

All outcomes

Blinding of outcome as-
sessment (detection bias) $\quad$ Unclear risk $\quad$ The blinding of outcome assessors was unclear.

All outcomes

\begin{tabular}{|c|c|c|}
\hline $\begin{array}{l}\text { Incomplete outcome data } \\
\text { (attrition bias) }\end{array}$ & Low risk & $\begin{array}{l}\text { The analysis included summary information from the screening logs on rea- } \\
\text { sons for loss and withdrawal. }\end{array}$ \\
\hline
\end{tabular}

All outcomes sons for loss and withdrawal.

Selective reporting (re- Low risk $\quad$ No reporting bias was detected.
porting bias)

porting bias)

\begin{tabular}{|c|c|c|}
\hline Other bias & Unclear risk & There was unclear risk of other biases. \\
\hline
\end{tabular}

EPP: extrapleural pneumonectomy

$\mathrm{CT}$ : computerized tomography

Gy: Gray

PTV: planning target volume

TNM: tumour/node/metastasis

Characteristics of excluded studies [ordered by study ID]

\begin{tabular}{ll}
\hline Study & Reason for exclusion \\
\hline Pass 1997 & $\begin{array}{l}\text { It didn't match the eligibility criteria as the intervention compared surgery, chemotherapy, im- } \\
\text { munotherapy and photodynamic therapy with surgery, chemotherapy and immunotherapy. }\end{array}$ \\
\hline Rea 2007 & Non-randomised study. \\
\hline Sauter 1995 & Non-randomised study. \\
\hline Yamanaka 2009 & Non-randomised study. \\
\hline
\end{tabular}

Characteristics of ongoing studies [ordered by study ID]

\section{NCT02040272}

Trial name or title

A study to determine if it is feasible to recruit into a randomised trial comparing (extended) pleurectomy decortication versus no pleurectomy decortication in patients with malignant pleural mesothelioma

\begin{tabular}{l} 
Methods \\
\hline Participants
\end{tabular}

Phase III

Interventions

Participants with histologically confirmed mesothelioma and disease confined to one hemithorax

Experimental arm: chemotherapy plus (Extended) pleurectomy decortication

Standard arm: chemotherapy only

Outcomes

Primary Outcome Measures

1. Ability to randomise 50 patients (TimeFrame: 24 months) 
NCT02040272 (Continued)

2. Ability to randomise 50 patients within the first 24 months or the ability to recruit 25 patients within any 6 month period

Secondary Outcome Measures

1. Survival from the time point of randomisation (time frame: follow-up for up to 5 years)

2. health-related quality of life as assessed using QLQ 30 and LC-13 scales (time frame: follow-up for up to 5 years)

\begin{tabular}{ll}
\hline Starting date & May 2015 \\
\hline Contact information & Eric Lim: e.lim@rbht.nhs.uk \\
\hline Notes & Sponsor: Royal Brompton \& Harefield NHS Foundation Trust \\
\hline
\end{tabular}

\section{NCT02153229}

Trial name or title

A randomised phase 2 Trial of radical pleurectomy and post-operative chemotherapy with or without intraoperative porfimer sodium -mediated photodynamic therapy for patients with epitheliod malignant pleural mesothelioma

\begin{tabular}{ll}
\hline Methods & Randomised phase II \\
\hline Participants & Participants with histologically confirmed mesothelioma and disease confined to one hemithorax \\
\hline Interventions & Experimental arm 1: chemotherapy plus radical pleurectomy plus photodynamic therapy \\
& Experimental arm 2: chemotherapy plus radical pleurectomy \\
\hline
\end{tabular}

\section{Outcomes}

Primary Outcome Measures:

Number of adverse events (time frame: 4 years)

\begin{tabular}{ll}
\hline Starting date & May 2014 \\
\hline Contact information & Sally.Mcnulty@uphs.upenn.edu \\
\hline Notes & Sponsor: Abramson Cancer Center of the University of Pennsylvania
\end{tabular}

\section{NCT02436733}

\section{Trial name or title}

Methods Randomised phase II

Participants

Participants with histologically confirmed mesothelioma
EORTC randomised phase II study of pleurectomy/decortication (P/D) preceded or followed by chemotherapy in patients with early stage malignant pleural mesothelioma.
Experimental: immediate P/D followed by three cycles of pemetrexed $500 \mathrm{mg} / \mathrm{m} 2 \mathrm{IV}$ and cisplatin 75 $\mathrm{mg} / \mathrm{m} 2 \mathrm{IV}$, both drugs given on day 1 , every three weeks for non-progressing patients.

Active Comparator: delayed P/D three cycles of pemetrexed $500 \mathrm{mg} / \mathrm{m} 2 \mathrm{IV}$ and cisplatin $75 \mathrm{mg} / \mathrm{m} 2$ IV, both drugs given on day 1 , every three weeks followed by $P / D$, for non-progressing patients.

\section{Outcomes}

Primary Outcome Measures


NCT02436733 (Continued)

1) Rate of success to complete the full treatment (time frame: 20weeks)

Secondary Outcome Measures

1) Loco-regional failure free survival (time frame: 6 months)

2) Overall survival (time frame: 15 months)

3)Treatment side-effects (time frame: 36 weeks)

\begin{tabular}{ll}
\hline Starting date & September 2016 \\
\hline Contact information & benedicte.marchal@eortc.be \\
\hline Notes & Sponsor: European Organization for Research and Treatment of Cancer (EORTC). \\
\hline
\end{tabular}

health-related quality of life

LC: lung cancer

IV: intravenous

QLQ: health-related quality of life questionnaire

\section{AP PEN DICES}

\section{Appendix 1. Cochrane Central Register of Controlled Trials Register (CENTRAL)}

\#1 MeSH descriptor: [Mesothelioma] explode all trees

\#2 MeSH descriptor: [Pleural Neoplasms] explode all trees

\#3 malignant mesothelioma

\#4 malignant pleural mesothelioma

\#5 pleural neoplasm*

\#6 pleural cancer*

$\# 7 \# 1$ or \#2 or \#3 or \#4 or \#5 or \#6

\#8 combin*

\#9 multimod* $^{\star}$

\#10 radical

\#11 \#8 or \#9 or \#10

$\# 12$ \#7 and \#11

\section{Appendix 2. MEDLINE (via PubMed) search strategy}

\#1,"Search mesothelioma[MeSH Terms]"

\#2,"Search pleural neoplasms[MeSH Terms]"

\#3,"Search "'mesothelioma, malignant""[Supplementary Concept]"

\#4,"Search "'malignant pleural mesothelioma"'"[Other Term]"

\#5,"Search malignant mesothelioma[Title/Abstract]"

\#6,"Search malignant pleural mesothelioma[Title/Abstract]"

\#7,"Search MPM[Title/Abstract]"

Radical multimodality therapy for malignant pleural mesothelioma (Review) 
\#8,"Search pleural neoplas*[Title/Abstract]"

\#9,"Search pleural cancer ${ }^{\star}[$ Title/Abstract]"

\#10,"Search \#1 OR \#2 OR \#3 OR \#4 OR \#5 OR \#6 OR \#7 OR \#8 OR \#9"

\#11,"Search "'antineoplastic agents"'[MeSH Terms]"

\#12,"Search antineoplastic combined chemotherapy protocols[MeSH Terms]"

\#13,"Search chemoradiotherapy[MeSH Terms]"

\#14,"Search combined modality therapy[MeSH Terms]"

\#15,"Search drug therapy[MeSH Terms]"

\#16,"Search hyperthermia, induced[MeSH Terms]"

\#17,"Search pleura/surgery[MeSH Terms]",1232,06:20:19

\#18,"Search pneumonectomy[MeSH Terms]"

\#19,"Search radiotherapy[MeSH Terms]"

\#20,"Search thoracic surgical procedures[MeSH Terms]"

\#21,"Search thoracotomy[MeSH Terms]"

\#22,"Search ""pleurectomy""[Other Term]"

\#23,"Search (("'decortication""'[Other Term] OR "'decortication/pleurectomy"'"[Other Term] OR "'decortication pleurectomy"'"[Other Term]))"

\#24,"Search radical[Other Term]"

\#25,"Search surgery[Other Term]"

\#26,"Search adjuvant[Title/Abstract]"

\#27,"Search chemoradiotherap*[Title/Abstract]"

\#28,"Search chemotherap*[Title/Abstract]"

\#29,"Search combination[Title/Abstract]"

\#30,"Search cytoreduc*[Title/Abstract]"

\#31,"Search decortication[Title/Abstract]"

\#32,"Search hypertherm[Title/Abstract]"

\#33,"Search multimod*[Title/Abstract]"

\#34,"Search neoadjuvant ${ }^{\star}[$ Title/Abstract]"

\#35,"Search photochemotherap [Title/Abstract]"

\#36,"Search pleurectom *[Title/Abstract]"

\#37,"Search pleuropneumonectom*[Title/Abstract]"

\#38,"Search pneumonectom*[Title/Abstract]"

\#39,"Search radical[Title/Abstract]"

\#40,"Search radiochemotherap*[Title/Abstract]"

\#41,"Search radiotherap*[Title/Abstract]" 
\#42,"Search resection[Title/Abstract]"

\#43,"Search surgery[Title/Abstract]"

\#44,"Search surgical[Title/Abstract]"

\#45,"Search thoracotom*[Title/Abstract]"

\#46,"Search trimodal*[Title/Abstract]"

\#47,"Search \#11 OR \#12 OR \#13 OR \#14 OR \#15 OR\#16 OR\#17 OR\#18 OR\#19 OR \#20 OR \#21 OR \#22 OR \#23 OR \#24 OR \#25 OR \#26 OR \#27 OR \#28 OR\#29 OR\#30 OR\#31 OR\#32 OR\#33 OR\#34 OR\#35 OR\#36 OR\#37 OR\#38 OR\#39 OR\#40 OR\#41 OR\#42 OR\#43 OR\#44 OR\#45 OR\#46"

\#48,"Search \#10 AND \#47"

\#49,"Search randomized controlled trial[Publication Type]"

\#50,"Search controlled clinical trial[Publication Type]"

\#51,"Search randomized[Title/Abstract]"

\#52,"Search placebo[Title/Abstract]"

\#53,"Search drug therapy[MeSH Subheading]"

\#54,"Search randomly[Title/Abstract]"

\#55, "Search trial[Title/Abstract]"

\#56,"Search groups[Title/Abstract]"

\#57,"Search \#49 OR \#50 OR \#51 OR \#52 OR \#53 OR \#54 OR \#55 OR \#56"

\#58,"Search animals[MeSH Terms]"

\#59,"Search humans[MeSH Terms]"

\#60,"Search \#58 NOT \#59"

\#61,"Search \#57 NOT \#60"

\#62,"Search \#48 AND \#61"

\section{Appendix 3. Embase (via Ovid) search strategy}

\#1 'mesothelioma'/exp

\#2 'pleura tumor'/exp

\#3 'mesothelioma':ab,ti

\#4 'malignant mesothelioma':ab,ti

\#5 'malignant pleural mesothelioma':ab,ti

\#6 'mpm':ab,ti

\#7 'pleural neoplas*':ab,ti

\#8 'pleural cancer ${ }^{\star}:$ ab,ti

\#9 \#1 OR \#2 OR \#3 OR \#4 OR \#5 OR \#6 OR \#7 OR \#8

\#10 'antineoplastic agent'/exp

\#11 'chemoradiotherapy'/exp

\#12 'multimodality cancer therapy'/exp 
\#13 'drug therapy'/exp

\#14 'hyperthermic therapy'/exp

\#15 'pleura'/exp AND 'surgery'/exp

\#16 'lung resection'/exp

\#17 'radiotherapy'/exp

\#18 'thorax surgery'/exp

\#19 'thoracotomy'/exp

\#20 'adjuvant':ab,ti

\#21 'chemoradiotherap*':ab,ti

\#22 'chemotherap ${ }^{\star \prime}: a b, t i$

\#23 'combination':ab,ti

\#24 'cytoreduc ${ }^{\star \prime}: a b, t i$

\#25 'decortication':ab,ti

\#26 'hypertherm':ab,ti

\#27 'multimod ${ }^{\star \prime}:$ ab,ti

\#28 'neoadjuvant ${ }^{\star \prime}: a b, t i$

\#29 'photochemotherap*':ab,ti

\#30 'pleurectom':ab,ti

\#31 'pleuropneumonectom':ab,ti

\#32 'pneumonectom*':ab,ti

\#33 'radical':ab,ti

\#34 'radiochemotherap ${ }^{\star \prime}: a b, t i$

\#35 'radiotherap ${ }^{\star \prime}: a b, t i$

\#36 'resection':ab,ti

\#37 'surgery':ab,ti

\#38 'surgical':ab,ti

\#39 'thoracotom*':ab,ti

\#40 'trimodal ${ }^{\star \prime}: \mathrm{ab}, \mathrm{ti}$

\#41 \#10 OR \#11 OR\#12 OR\#13 OR\#14 OR\#15 OR \#16 OR\#17 OR\#18 OR\#19 OR \#20 OR \#21 OR \#22 OR\#23 OR \#24 OR\#25 OR\#26 OR\#270R \#28 OR \#29 OR \#30 OR \#31 OR \#32 OR \#33 OR \#34 OR \#35 OR \#36 OR \#37 OR \#38 OR \#39 OR \#40

\#42 \#9 AND \#41

\#43 'crossover procedure'/exp OR 'double-blind procedure'/exp OR 'randomized controlled trial'/exp OR 'single-blind procedure'/exp OR random* ORfactorial* OR crossover ${ }^{\star}$ OR cross NEXT/1 over* OR placebo* OR doubl* NEAR/1 blind* OR singl ${ }^{\star}$ NEAR/1 blind* OR assign* OR allocat* ORvolunteer*

\#44 \#42 AND \#43

Radical multimodality therapy for malignant pleural mesothelioma (Review) 


\section{CONTRIBUTIONS OF AUTHORS}

Guarantor of the review: Omar Abdel-Rahman

Conceiving and designing the review: Omar Abdel-Rahman, Zeinab Elsayed, Hadeer Mohamed and Mostafa Eltobgy

Providing a methodological perspective: Omar Abdel-Rahman

Providing a clinical perspective: Omar Abdel-Rahman and Zeinab Elsayed

Writing the review: Omar Abdel-Rahman, Zeinab Elsayed, Hadeer Mohamed and Mostafa Eltobgy

\section{DECLARATIONS OF INTEREST}

Omar Abdel-Rahman: None known

Zeinab Elsayed: None known

Hadeer Mohamed: None known

Mostafa Eltobgy: None known

\section{SOURCES OF SUPPORT}

\section{Internal sources}

- None, Other.

\section{External sources}

- None, Other.

\section{DIFFERENCES BETWEEN PROTOCOL AND REVIEW}

We added the following statement to the measure of effect section: "we also used hazard ratios as measure of effect for time-to-event outcomes (overall survival)" in order to clarify this point.

Some sections of the background were rewritten to improve clarity of the meaning.

We added the following outcomes to the summary of findings table "postoperative complications and treatment-related death" in order to clarify the findings of these outcomes.

\section{N DEX TERMS}

\section{Medical Subject Headings (MeSH)}

Antineoplastic Agents [ ${ }^{\star}$ therapeutic use]; Combined Modality Therapy [ ${ }^{*}$ methods]; Lung Neoplasms [mortality] [*therapy]; Mesothelioma [mortality] [ ${ }^{\star}$ therapy]; Mesothelioma, Malignant; Platinum Compounds [therapeutic use]; Pneumonectomy [ ${ }^{*}$ methods]; Radiotherapy Dosage; Randomized Controlled Trials as Topic

\section{MeSH check words}

Humans 